\title{
Snow cover sensitivity to horizontal resolution, parameterizations, and atmospheric forcing in a land surface model
}

\author{
Emanuel Dutra, ${ }^{1,2,4}$ Sven Kotlarski, ${ }^{2}$ Pedro Viterbo, ${ }^{1,3}$ Gianpaolo Balsamo, ${ }^{4}$ \\ Pedro M. A. Miranda, ${ }^{1}$ Christoph Schär, ${ }^{2}$ Peter Bissolli, ${ }^{5}$ and Tobias Jonas ${ }^{6}$ \\ Received 11 April 2011; revised 25 July 2011; accepted 19 August 2011; published 10 November 2011.
}

[1] This paper assesses the impacts of horizontal resolution, snow physics, and atmospheric forcing in snow cover simulations by the European Centre for Medium-Range Weather Forecasts (ECWMF) land surface model Hydrology Tiled ECMWF Scheme for Surface Exchanges (HTESSEL). Off-line simulations are carried out forced by the ECMWF deterministic short-term weather forecasts (WFC) with a resolution of $25 \mathrm{~km}$ from March 2006 to June 2010. The horizontal-resolution impact on snow cover is addressed by performing simulations at 25,80 , and $200 \mathrm{~km}$ forced by WFC. The impact of atmospheric forcing on snow cover is assessed by forcing the model additionally with the ECMWF Era-Interim (ERAI) reanalysis, at $80 \mathrm{~km}$ resolution. Snow physics effects are analyzed by performing an extra simulation forced by WFC using a different snow scheme. The simulations are validated against four independent observational data sets: (1) snow water equivalent (SWE) over Switzerland; (2) snow cover duration in Europe (SNOWCLIM); (3) interactive multisensor snow and ice-mapping system (IMS) snow cover; and (4) Moderate Resolution Imaging Spectroradiometer (MODIS) surface albedo. ERAI forced simulations show a systematic underestimation of SWE and snow cover fraction, which is due to an underprediction of snowfall by ERAI. The snow physics experiment highlights the sensitivity of the model to the partitioning between rainfall and snowfall when rainfall interception in the snowpack is neglected. The horizontal resolution has a crucial role in characterizing the snow cover over complex terrain (e.g., orographic areas, coastal and lakes regions). However, improved snow physical parameterizations and meteorological forcing are shown to be the key elements to achieve more accurate simulations of the snowpack and of the snow-atmosphere interactions, also over flat terrain.

Citation: Dutra, E., S. Kotlarski, P. Viterbo, G. Balsamo, P. M. A. Miranda, C. Schär, P. Bissolli, and T. Jonas (2011), Snow cover sensitivity to horizontal resolution, parameterizations, and atmospheric forcing in a land surface model, J. Geophys. Res., 116, D21109, doi:10.1029/2011JD016061.

\section{Introduction}

[2] The extent and variability of snow cover are important parameters in weather and climate prediction systems because of their effects on the surface energy and water balance, leading to a strong dependence of, for instance, surface temperature on the presence or absence of snow cover [Armstrong and Brun, 2008; Dutra et al., 2010a; Hazeleger et al., 2010]. There is evidence of links between large-scale snow cover and hemispheric circulation anomalies in the Northern

\footnotetext{
${ }^{1}$ Centro de Geofísica da Universidade de Lisboa, Instituto Dom Luiz, University of Lisbon, Lisbon, Portugal.

${ }^{2}$ Institute for Atmospheric and Climate Science, ETH Zurich, Switzerland.

${ }^{3}$ Institute of Meteorology, Lisbon, Portugal.

${ }^{4}$ European Centre for Medium-Range Weather Forecasts, Reading, UK.

${ }^{5}$ Deutscher Wetterdienst, Offenbach am Main, Germany.

${ }^{6}$ WSL Institute for Snow and Avalanche Research SLF, Davos, Switzerland.

Copyright 2011 by the American Geophysical Union. 0148-0227/11/2011JD016061
}

Hemisphere (NH) [e.g., Fletcher et al., 2009]. On smaller spatial scales, snow cover is an important component of local- and regional-scale energy and water budgets, especially in mountainous areas [Beniston et al., 2010; Schär et al., 2004]. The latter, however are often poorly represented in climate models. More than one sixth of the Earth's population relies on glacier and seasonal snowpacks for their water supply, and the consequences of hydrological changes under the influence of rising levels of greenhouse gases is likely to be severe [Barnett et al., 2005]. Last, but not least, snow may affect daily life considerably, e.g., in terms of transport networks and tourism, and therefore reliable estimates of future snow conditions are needed.

[3] Snow temporal evolution in land surface models (LSMs) is mainly determined by the atmospheric forcing and model physics. When LSMs are used within numerical weather prediction (NWP) or climate models, the forcing is directly provided by the atmospheric component, and the landatmosphere coupling, including feedback mechanisms, is fully represented. However, off-line or stand-alone simula- 
tions are very common in intercomparison studies [e.g., Boone et al., 2004; Bowling et al., 2003; Rutter et al., 2009] and model evaluation and development [e.g., Dutra et al., 2010a; Livneh et al., 2010; Wang et al., 2010]. Once snow settles on the ground, its temporal evolution is mostly controlled by the atmosphere that provides the upper boundary conditions for the physics and parameterizations of the snowpack. There is a wide variety of physical representations of the snowpack water and energy balance, ranging from single-layer [e.g., Dutra et al., 2010a] to detailed multilayer representations of snow stratigraphy [e.g., Brun et al., 1992]. Other processes such as snow albedo and snow density evolution are based on parameterizations. On a gridbox scale, the effects of vegetation [Wang et al., 2010] and subgrid-scale variability [Liston, 2004] on snow cover are still topics of ongoing research. Because of the high spatial variability of snow processes and the importance of topography, resolution issues generally play an important role [e.g., Giorgi et al., 2003].

[4] The goal of this study is to assess the impacts of atmospheric forcing, snow parameterization, and horizontal resolution on simulating snow in a state-of-the-art LSM, using independent data sets to validate the simulations. The assessment is performed by conducting global off-line simulations with the European Centre for Medium-Range Weather Forecasts (ECMWF) LSM Hydrology Tiled ECMWF Scheme for Surface Exchanges Over Land (HTESSEL) [Balsamo et al., 2009]. The off-line simulations methodology, although recurrent in LSM validations, has shortcomings that are due to the associated nature of the one-way coupling and the absence of an atmospheric response to land surface processes. Nevertheless, off-line simulations can be an advantage since they isolate the LSM response to the various factors in the analysis.

[5] The effects of horizontal resolution are analyzed by performing off-line simulations of HTESSEL at 25, 80, and $200 \mathrm{~km}$ horizontal resolution forced by the ECMWF deterministic weather forecasts (WFC). Jung et al. [2010] and references therein report the major changes since 2005 in the physical parameterizations of the ECMWF model. WFC have been available at $25 \mathrm{~km}$ resolution globally since February 2006 and are based on a state-of-the-art NWP model and data assimilation system. The WFC provides a high spatial and temporal resolution data set covering the entire globe during four recent winter seasons. These characteristics, in combination with the continuous development and validation performed at ECWMF [e.g., Jung et al., 2010; Richardson et al., 2009], guarantee a realistic atmospheric forcing required for this study. The HTESSEL simulations with different resolution are forced with the same atmospheric fields. This can be interpreted as a proxy for comparison of resolved versus unresolved spatial variability from the 25 to the $200 \mathrm{~km}$ resolution simulations. The subject of subgrid-scale variability on land surface processes has been addressed by many studies. For example, Liston [2004] proposed a representation of subgrid snow distribution within a grid box showing significant impacts on snow cover evolution in a regional climate model. Giorgi et al. [2003] developed a mosaic-type parameterization of subgrid-scale topography and land use in a regional climate model to bridge the scale gap between climate models and surface hydrological processes. This approach improved the simulation of snow and runoff at high-elevation sites in the Alpine region [Im et al., 2010]. However, the increase of horizontal resolution, or enhanced representation of subgridscale variability, in regional climate models is hampered by the lack of adequate station observations that can capture the complex climatology and provide means to validate model simulations [Rauscher et al., 2010]. Nevertheless, this problem has been mitigated in recent years with the increasing availability of high-resolution remote sensing and gridded in situ network data.

[6] The near-surface atmospheric fields of the ECMWF Re-Analysis ERA-Interim (ERAI) [Dee et al., 2011] for the same period as the WFC, are also used to force HTESSEL. This allows for a comparison between the two forcing data sets and their effects on the simulated snow cover. Among the differences that are due to different atmospheric model versions and assimilation systems, WFC and ERAI mainly differ in the horizontal resolution of the atmospheric model (25 and $80 \mathrm{~km}$, respectively). The foremost difference between the two forcing data sets is expected to be precipitation. The largest effect can be expected in complex terrain regions, where the WFC should, in principle, have a better representation of orographic-driven events. This is an important factor to evaluate, since model simulations of snow cover and snow mass are sensitive to precipitation, as shown by Carrera et al. [2010] in the Canadian Rockies. The impact of the model physics is assessed by performing an extra simulation forced with the WFC but using an older version of the HTESSEL snow scheme. The old and the new snow schemes, as well as their comparison, are described by Dutra et al. [2010a]. Both additional simulations, forced with ERAI and with the old snow physics, were performed at an intermediate resolution $(80 \mathrm{~km})$. In summary, we show the impact of running the model at different resolutions, forced by the same atmospheric conditions, and the impact of using different snow physics and different atmospheric forcings at the same resolution.

[7] For model evaluation, results are compared against four different and independent data sets: (1) a time series of daily mean snow mass over Switzerland, (2) mean monthly snow cover duration (SCD) in Europe, (3) daily snow cover maps of the Northern Hemisphere (NH), and (4) monthly maps of surface albedo. The first two data sets are based on in situ observations, while the remaining two are remotely sensed products. The model description, simulation setups, and observational data sets are presented in the next section. The results of the different simulations to assess the impacts of atmospheric forcing, model physics, and horizontal resolution are presented and discussed in section 3. The main conclusions of the study are summarized in section 4 .

\section{Methods}

\subsection{Model Description}

[8] HTESSEL computes the land surface response to atmospheric forcing and estimates the surface water and energy fluxes and the temporal evolution of soil temperature, moisture content, and snowpack conditions. At the interface to the atmosphere, each grid box is divided into fractions (tiles), with up to six fractions over land (bare ground, low and high vegetation, intercepted water, and shaded and exposed snow). Vegetation types and cover fractions are derived from an 


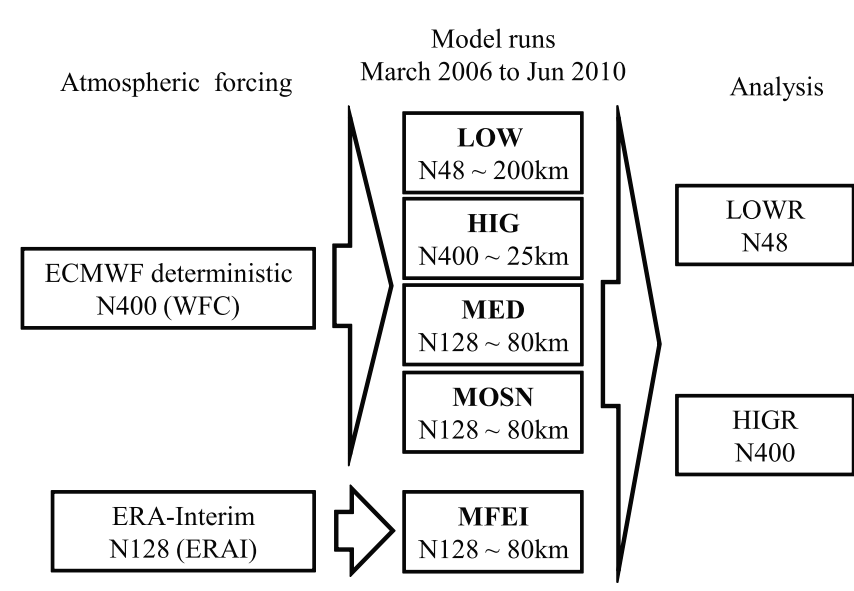

Figure 1. Experimental design: atmospheric forcing interpolation from simulations grid from left to center and model output interpolation to analysis grid from center to right.

external climate database, based on the Global Land Cover Characteristic [Loveland et al., 2000]. The grid-box surface fluxes are calculated separately for each tile, leading to a separate solution of the surface energy balance equation and the skin temperature. The latter represents the interface between the surface and the atmosphere. The surface albedo is similar for all land tiles within a grid box except for those covered with snow. The climate database provides the snow-free background albedo on a monthly basis, produced for the combined 1982-1990 years and computed using the method of Sellers et al. [1996] and parameters by Los et al. [2000].

[9] Below the surface, the vertical transfer of water and energy is performed using four vertical layers to represent soil temperature and moisture. Soil heat transfer follows a Fourier law of diffusion, modified to take into account soil water freezing or melting [Viterbo et al., 1999]. Water movement in the soil is determined by Darcy's law, and surface runoff follows a variable infiltration rate considering that runoff can occur on a fraction of the grid point, accounting for the subgrid variability of orography [Balsamo et al., 2009]. In the case of partially (or fully) frozen soil, water transport is limited, leading to a redirection of most of the rainfall and snowmelt to surface runoff when the uppermost soil layer is frozen. The snow scheme [Dutra et al., 2010a] represents an additional layer on top of the soil, with an independent prognostic thermal and mass content. The snowpack is represented by a single snow temperature, snow mass, snow density, snow albedo, and a treatment for snow liquid water in the snowpack. The snow scheme considers only one snowpack in the grid box (same conditions over the exposed and vegetated fractions) and does not account for snow interception by the canopy. HTESSEL is part of the integrated forecast system at ECMWF, with operational applications ranging from short to seasonal weather forecasts, and research including lake modeling [Dutra et al., 2010b] and runoff routing [Pappenberger et al., 2010].

\subsection{Simulations Setup}

[10] Near-surface meteorology and surface fluxes from WFC were used to force HTESSEL in off-line mode.
Near-surface meteorology includes instantaneous values at a $3 \mathrm{~h}$ interval of air temperature, wind speed, specific humidity from the lowest model level (level 91, approximately $10 \mathrm{~m}$ above the surface), and surface pressure. These correspond to the $3-12 \mathrm{~h}$ forecast interval from initial conditions at 00:00 and 12:00 UTC. Surface fluxes include downward solar and thermal radiation and liquid and solid precipitation representing $3 \mathrm{~h}$ averages taken from the 9-21 h forecasts initialized at 00:00 and 12:00 UTC to avoid the initial spin-up in precipitation.

[11] All simulations were performed from March 2006 to June 2010 for the NH. The initial conditions were derived from a 2 year spin-up (March 2006 to February 2008), using the surface state by the end of February 2008 to initialize the model for the main simulation in March 2006. The first six months were not included in the analysis to avoid possible spin-up effects that are due to adjustments to the initial conditions. This period was chosen to exploit the high resolution of the forecasts. In February 2006 ECMWF increased the horizontal resolution of the deterministic forecast from TL511 $(\sim 40 \mathrm{~km})$ to TL799 (Gaussian reduced grid $\mathrm{N} 400, \sim 25 \mathrm{~km}$ resolution) and the number of vertical levels from 60 to 91 . From 2006 to 2010, there was only one change in resolution of the deterministic forecast to T1279 $(\sim 16 \mathrm{~km})$ in January 2010 . Within the same period, many other changes occurred in the model physics and data assimilation system.

[12] The effects of the horizontal resolution of the snow scheme are assessed by performing three off-line simulations with different land surface resolutions, each forced by the WFC: (1) high resolution (HIG; same resolution as the forcing, $25 \mathrm{~km}$ ), (2) medium resolution (MED; Gaussian reduced grid N128, $80 \mathrm{~km}$ ), and (3) low resolution (LOW; Gaussian reduced grid N48, $200 \mathrm{~km}$ ) (see Figure 1). These three resolutions were selected as representing the typical resolutions of global atmospheric models used for mediumrange weather forecasts and regional climate simulations $(25 \mathrm{~km})$, atmospheric reanalysis $(80 \mathrm{~km})$, and global climate simulations $(200 \mathrm{~km})$. The forcing for the two lowerresolution experiments was upscaled from the WFC using a conservative interpolation and accounting for altitude differences: air temperature with a constant lapse rate of $6.5 \mathrm{~K}$ $(1000 \mathrm{~m})^{-1}$, surface pressure with a barometric correction, and longwave downward radiation with a constant adjustment of $2.8 \mathrm{~W} \mathrm{~m}^{-2}(100 \mathrm{~m})^{-1}$ [Wild et al., 1995]. These corrections were applied prior to the interpolation to adjust the variables to a common level (target model orography). For specific humidity, first, relative humidity was calculated and interpolated and then transformed again to specific humidity but using the corrected surface pressure and air temperature. No corrections were performed to the remaining forcing fields (wind speed, shortwave radiation and liquid and solid precipitation). The applied corrections only account for the thermodynamic differences that are due to different altitudes. They do not account for the spatial and temporal variability of the lapse rate [e.g., Kotlarski et al., 2010] and do not change the partitioning of precipitation between the solid and liquid phases that was kept as in the WFC.

[13] The impact of the forcing on snow cover is assessed by forcing HTESSEL with the ECMWF Re-Analysis ERAInterim (ERAI) near-surface atmospheric fields and fluxes (MFEI) and comparing with the simulation forced by WFC 
a)Winter 2008/09 total precipitation (ERAI-WFC)

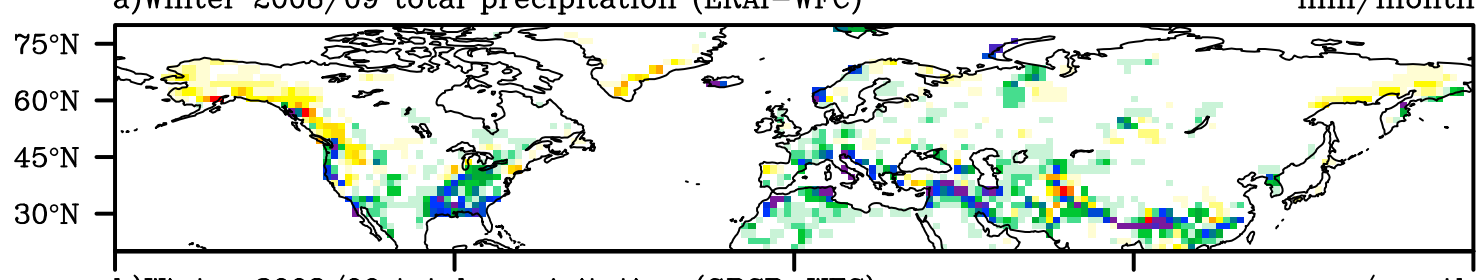

b)Winter 2008/09 total precipitation (GPCP-WFC)

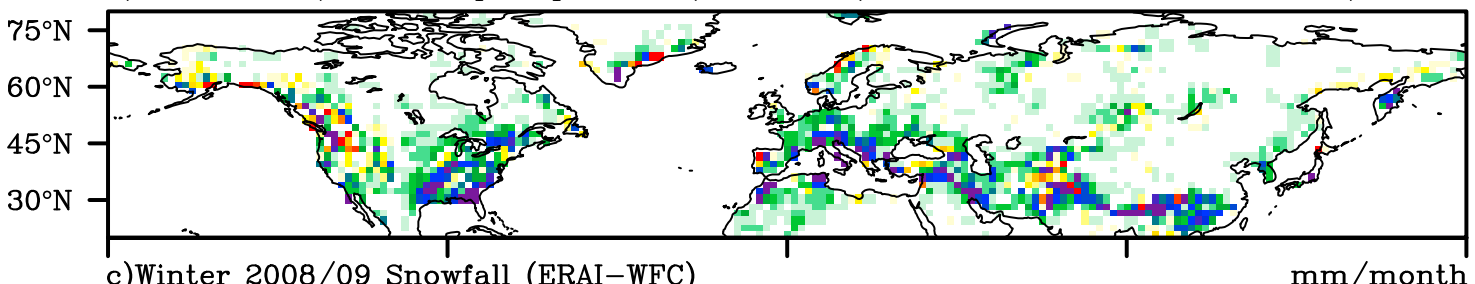

c)Winter 2008/09 Snowfall (ERAI-WFC)

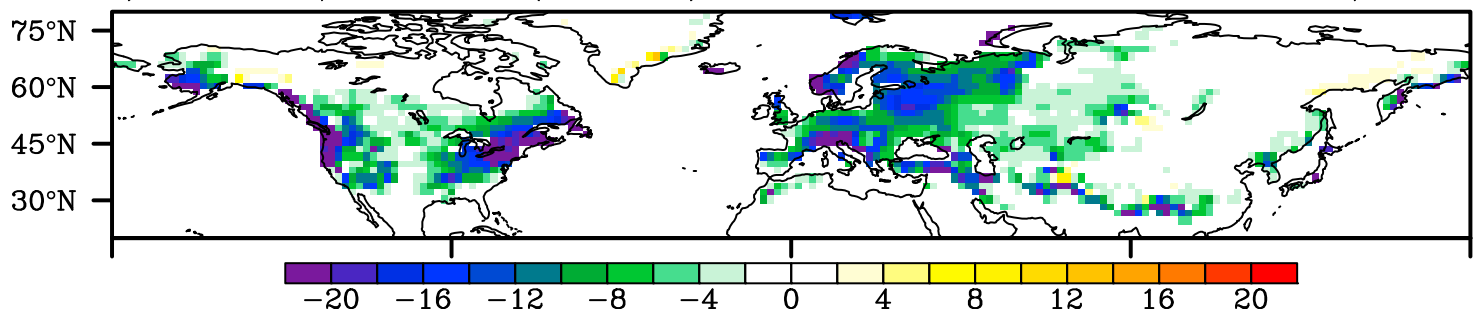

Figure 2. Mean differences of total precipitation between (a) ERAI-WFC, (b) GPCP-WFC, and (c) snowfall ERAI-WFC for the 2008-2009 winter season.

at the same resolution (MED). ERAI provides a temporally consistent atmospheric forcing that has been used in other off-line studies [e.g., Dutra et al., 2010b]; it differs from the WFC in the horizontal resolution $(\sim 80 \mathrm{~km})$, the atmospheric model physics, and the assimilation system. Total precipitation and the partitioning between liquid and solid phases are crucial forcing fields for an accurate prediction of snow conditions. Figure 2 presents the differences of total precipitation between ERAI and the Global Precipitation Climatology Project (GPCP, v2.1 2.5 $\times 2.5^{\circ}$ resolution) [Huffman et al., 2009], compared against the WFC for the 2008-2009 winter season. It is possible to identify several regions with either underestimation or overestimation of precipitation by ERAI and GPCP when compared with the WFC, which are mainly located near complex terrain regions, displaying some variability during the four years analyzed (not shown). The main difference is the partitioning between solid and liquid phases between ERAI and the WFC, where the WFC has a higher rate of snowfall (Figure 2c). In the ECMWF atmospheric model, precipitation can be generated as liquid or solid and phase changes can occur as precipitation falls through the atmospheric column, defining the exact amount of rainfall and snowfall when it reaches the surface. Before October 2007 (including the code version used for ERAI), precipitation generated from clouds in the mixed-phase zone $\left(0^{\circ} \mathrm{C}\right.$ to $\left.-23^{\circ} \mathrm{C}\right)$ was partitioned according to temperature so that rain could exist below $0^{\circ} \mathrm{C}$ (all rain production at $0^{\circ} \mathrm{C}$, all snow production at $-23^{\circ} \mathrm{C}$, and a mix in between). After October 2007, an additional freezing term was introduced that converts rain to snow for temperatures below $0^{\circ} \mathrm{C}$. This led to an increase in snowfall wherever there was precipitation formed from clouds between $0^{\circ} \mathrm{C}$ and $-23^{\circ} \mathrm{C}$. ERAI overpredicts the occurrence of freezing rain, which should have been snowfall. During the 2006 2007 winter, ERAI and WFC have a similar partition between rainfall and snowfall (not shown).

[14] The land surface snow physics impact on snow cover is assessed by performing an extra simulation at MED resolution driven by WFC and using an old snow scheme (MOSN). The old snow scheme was part of HTESSEL and used by the ECMWF forecasting system until December 2009 (including ERAI). When compared with the new snow scheme (NEW), three main differences can be identified: (1) dry versus wet snow in NEW including rainfall interception in the snowpack; (2) simple exponential increase of snow density versus a more physically based formulation in NEW, and (3) constant forest albedo in the presence of snow versus a vegetation-cover-type dependence based on observations in NEW. The snow cover fraction (SCF) is parameterized as a linear function of snow mass between 0 (no snow) and $15 \mathrm{~mm}$ (fully snow covered) in OLD. NEW follows a similar approach, but using snow depths between 0 and $10 \mathrm{~cm}$ (fully snow covered), representing the hysteresis of snow cover between the beginning of the cold season (low snow densities) and the later stage of ablation (high snow densities). Snow albedo in exposed areas evolves with an exponential or linear decay in melting and nonmelting conditions, respectively, in both NEW and OLD. In OLD the snow albedo is reset to its maximum value $(0.85)$ when snowfall rate $>1 \mathrm{~kg} \mathrm{~m}^{-2} \mathrm{~h}^{-1}$ while NEW assumes a continuous reset to the maximum reached after an accumulated value of $10 \mathrm{~cm}$ of fresh snow. In OLD the albedo of shaded snow (snow under high vegetation) was set to a constant value of 0.15 , while in NEW it depends on the vegetation type derived from remotely sensed data [Moody et al., 2007]. Dutra et al. [2010a] describe the differences between the 
two snow schemes in detail. The major changes in NEW are associated with an increased thermal snow insulation, with impacts on the surface water balance and a better representation of snow cover, especially during the melting season.

[15] The simulation setup is summarized in Figure 1. The impact of horizontal resolution on snow cover is analyzed by comparing LOW, MED, and HIG; the impact of atmospheric forcing by comparing MED and MFEI; and the impact of the snow physics by comparing MED and MOSN. All simulations were postprocessed and interpolated to two common resolutions: (1) low resolution (LOWR; $200 \mathrm{~km}$ ) to assess large-scale temporal variability, and (2) high resolution (HIGR; $25 \mathrm{~km}$ ) to study spatial patterns. A spatial conservative interpolation, as for the atmospheric forcing, was applied to guarantee a fair comparison between the different resolution simulations. The conservative interpolation of any variable to the grid point $y_{j}$ of the target $Y$ grid from the original $X$ grid is given by

$$
y_{j}=\frac{1}{\sum_{i=1}^{n} w_{i}} \sum_{i=1}^{n} w_{i, j} x_{i},
$$

where $x_{i}$ is the value of the variable to be interpolated on grid point $i$ of grid $X, w_{i, j}$ is the intersection area of the grid points $y_{j} \cap x_{i}$, and $n$ is the number of grid points of grid $X$.

\subsection{Observations}

[16] Four independent observational data sets are used for model validation: (1) snow water equivalent over Switzerland, (2) snow cover duration over Europe, (3) snow cover, and (4) surface albedo.

[17] The first reference data set (SLF) was provided by the WSL Institute for Snow and Avalanche Research SLF based on ground observations of three snow-monitoring networks in Switzerland. For this study we used daily snow depth data from a subset of 203 stations to allow a gap-free data set that represents all Swiss snow meteorological regions [Laternser and Schneebeli, 2003] and elevation bands as homogeneously as possible. The snow data were interpolated to a $25 \mathrm{~km}$ grid using methods particularly developed for snow depth mapping [cf. Foppa et al., 2007]. The resulting snow depth maps were converted into snow-waterequivalent (SWE) maps using a parametric snow density model based on that by Jonas et al. [2009]. This model is particularly suited as it was calibrated using 11,000 snow profiles from the same snow-monitoring networks that provided the snow depth data for this study.

[18] The second reference data set is SNOWCLIM, a snow climate monitoring project of Deutscher Wetterdienst (DWD, German Meteorological Service). The data are based on daily snow depths measured at 06:00 UTC at synoptic stations received via the Global Telecommunication System (GTS) of the World Meteorological Organization (WMO) and quality controlled at DWD. Various snow quantities, aggregated to monthly data, are derived from the daily snow depth for each station, among them the number of snow days (defined as the number of days for each month that had snow with a depth of at least $1 \mathrm{~cm}$ ) which is used in this study. These monthly station data are interpolated onto a grid of $0.1^{\circ} \times 0.1^{\circ}$ resolution in latitude and longitude for the area of Europe and the Middle East, using a linear regression with latitude, longitude, and altitude and afterward the interpolation method "radial basis functions, multiquadratic." Radial basis functions show similar results as ordinary kriging, as shown by Hogewind and Bissolli [2011].

[19] The interactive multisensor snow and ice mapping system (IMS) [Helfrich et al., 2007; Ramsay, 1998] snow cover product represents the third observational reference data set that has been compared with model simulations. The IMS daily snow cover maps of the $\mathrm{NH}$ have been available at a nominal resolution of $24 \mathrm{~km}$ since February 1997 and of $4 \mathrm{~km}$ since February 2004, the latter being used in this study. The snow cover maps are produced every day in a workstation-based application in which various remote sensing products and surface observations are processed by analysts. The IMS has been evaluated against other satellitebased snow products [Brown et al., 2007] and in situ observations [Brubaker et al., 2005], showing a good performance during the core winter season and some deficiencies in the accumulation and melting periods that are common to other satellite-based products. There is a wide range of applications to this product, including data assimilation [Drusch et al., 2004] and validation of LSMs [e.g., Carrera et al., 2010; Dutra et al., 2010a; Livneh et al., 2010; Sheffield et al., 2003].

[20] The fourth reference data set is based on the Moderate Resolution Imaging Spectroradiometer (MODIS) albedo product MCD43C3, which provides data describing both directional hemispheric reflectance (black-sky albedo) and bihemispherical reflectance (white-sky albedo) in seven different bands and aggregated bands. Data from the Terra and Aqua platforms are merged in the generation of the product that is produced every 8 days with 16 days of acquisition and available on a $0.05^{\circ}$ global grid. The accuracy and quality of the product have been studied by several authors in different locations, reporting root-mean-square errors of 0.0130 over 8 field sites in the United States [Salomon et al., 2006] and root-mean-square errors of 0.07 over 16 field sites in Greenland [Stroeve et al., 2005].The MODIS albedo product has already served as reference for model validation [e.g., Dutra et al., 2010a; Wang and Zeng, 2010; Zhou et al., 2003]. In this study, the MODIS whitesky broadband shortwave albedo is compared against the off-line simulations.

[21] The IMS snow cover maps and MODIS surface albedo were aggregated to LOWR and HIGR resolutions. The spatial aggregation was performed using the relation in equation (1), setting $w_{i, j}$ to one (or zero) if the pixel (from IMS or MODIS) is inside (or outside) the grid point $y_{j}$. This is a reasonable approximation since the resolutions of IMS $(4 \mathrm{~km})$ and MODIS (about $5.6 \mathrm{~km}$ ) are much smaller than LOWR $(200 \mathrm{~km})$ or HIGR $(25 \mathrm{~km})$. This procedure also allows the transformation of the IMS binary product (snow covered or snow free) to a grid point SCF.

[22] All observation data sets have various sources of uncertainty. These are errors in the measurements, the retrieval algorithms, and the gridding procedure, and differences in resolution. We have not discussed any uncertainty level of the observation data sets since its quantification is complex, and the main goal of this study is rather the comparison of different simulation setups than a verification of a single experiment. The uncertainty of observations does 
Table 1. Region Definitions with Latitude and Longitude Limits, Area, Mean Altitude Above Sea Level, Mean Standard Deviation of Orography (Std Oro), and Fraction of the Region Occupied by Forests, Derived From the $80 \mathrm{~km}$ Climate Fields

\begin{tabular}{|c|c|c|c|c|c|}
\hline & Region & $\begin{array}{c}\text { Area } \\
\left(10^{6} \mathrm{~km}^{2}\right)\end{array}$ & $\begin{array}{l}\text { Elevation } \\
\text { (m) }\end{array}$ & $\begin{array}{l}\text { Std Oro } \\
\text { (m) }\end{array}$ & $\begin{array}{c}\text { Forest } \\
(\%)\end{array}$ \\
\hline Alps (AL) & $5^{\circ} 15^{\circ} \mathrm{E} 44^{\circ} 48^{\circ} \mathrm{N}$ & 0.28 & 912 & 383 & 64 \\
\hline Mid-Europe (ME) & $2^{\circ} 16^{\circ} \mathrm{E} 48^{\circ} 55^{\circ} \mathrm{N}$ & 0.66 & 243 & 74 & 57 \\
\hline Eastern Europe (EE) & $16^{\circ} 30^{\circ} \mathrm{E} 44^{\circ} 55^{\circ} \mathrm{N}$ & 1.21 & 254 & 83 & 41 \\
\hline Scandinavia (SC) & $5^{\circ} 30^{\circ}$ E $55^{\circ} 70^{\circ} \mathrm{N}$ & 1.37 & 275 & 84 & 72 \\
\hline Himalaya (HY) & $65^{\circ} 110^{\circ}$ E $22^{\circ} 47^{\circ} \mathrm{N}$ & 11.35 & 1906 & 272 & 12 \\
\hline Rockies (RK) & $-125^{\circ}-100^{\circ} \mathrm{E} 44^{\circ} 48^{\circ} \mathrm{N}$ & 3.64 & 1352 & 217 & 22 \\
\hline Central Eurasia (CE) & $53^{\circ} 110^{\circ} \mathrm{E} 48^{\circ} 75^{\circ} \mathrm{N}$ & 8.65 & 421 & 83 & 43 \\
\hline Central Canada (CC) & $-115^{\circ}-90^{\circ}$ E $48^{\circ} 75^{\circ} \mathrm{N}$ & 3.53 & 385 & 45 & 42 \\
\hline N. Hemisphere (NH) & $-180^{\circ} 180^{\circ}$ E $20^{\circ} 80^{\circ} \mathrm{N}$ & 67.57 & 753 & 148 & 38 \\
\hline
\end{tabular}

not impact the comparison itself because all simulations are compared with the same observational data set. However, the uncertainty has been considered by using various observation data sets from different sources (in situ and satellite).

\section{Results}

[23] In the following section the HTESSEL off-line simulations are compared with observational data sets in eight regions of the Northern Hemisphere poleward of $20^{\circ} \mathrm{N}$. Table 1 presents the regions and their main characteristics: surface area, mean altitude above sea level, orographic variability (standard deviation of orography), and fraction of the region occupied by forests (high vegetation tile in HTESSEL), derived from the $80 \mathrm{~km}$ climate fields. We analyzed four different regions in Europe, following the definition of Christensen and Christensen [2007]: the Alps (AL), characterized by complex terrain orography; Scandinavia (SC), dominated by forests; mid-Europe (ME); and eastern Europe (EE). The remaining four areas include two mountainous regions, the Himalayas (HY) and the Rockies (RK), and two rather flat regions with a reduced fraction of forests, central Eurasia (CE) and central Canada (CC). The regions were defined in order to sample different combinations of vegetation and orography in the Northern Hemisphere, where seasonal snow cover plays an important role. In the discussion, three different measures of snow cover are used: (1) snow cover duration (SCD number of days covered by snow in a grid box or averaged in a region); (2) snow-covered area $\left(\mathrm{SCA} \mathrm{km}^{2}\right.$, also referred as snow cover extent, denoting the area of a certain region that is covered by snow), and (3) snow cover fraction (SCF, ratio between SCA and total area of a grid point or region). The next section is focused on Switzerland, which is part of the subregion AL but which was not previously defined as a study region, since the SLF SWE observational estimates are available for Switzerland only. This is a unique data set for LSM validation of the daily SWE over a complex terrain region.

\subsection{Snow Mass in Switzerland}

[24] Figure 3 compares the time series of simulated mean SWE over Switzerland against the SLF observations. The observations show a marked interannual variability with maximum SWEs of 159, 236, 337, and $190 \mathrm{~mm}$ for 20062007, 2007-2008, 2008-2009, and 2009-2010, respectively. The LOW simulations show a systematic underestimation of SWE and an early melting. Part of the underestimation of SWE is due to lower values of snowfall when compared with MED or HIG. Although the forcing was upscaled from the WFC using a mass conservative approach, over Switzerland there are 66,8 , and 1 grid points at the HIG, MED, and LOW resolutions, respectively. All simulations, except $\mathrm{HIG}$, were postprocessed to HIGR resolution. Table 2 presents the accumulated water fluxes from 1 November to 1 March in 2006-2007 and 2007-2008 averaged over Switzerland. While both MED and HIG were forced with very similar rainfall and snowfall amounts, LOW only received about $60 \%-70 \%$ of the snowfall. In addition, LOW is subject to a stronger snowmelt, $+34 \%(+164 \%)$ compared with $\mathrm{HIG}$ and $-4 \%(+116 \%)$ compared with MED in 2006-2007 (2007-2008). Hence, the lower SWE in LOW compared with HIG or MED is caused by two factors: (1) lower snowfall rates that are due to resolution and (2) higher melting rates. While the first aspect is associated with the modeling framework of this study, the second shows the importance of resolution in land surface modeling. Higher altitudes in complex terrain regions will mostly have colder and thicker snowpacks and later melting than lower altitudes, even with similar snowfall rates.

[25] During 2006-2007 all simulations underestimate SWE, but HIG is closest to SLF. In the other three years both HIG and MED show a similar SWE evolution until the beginning of April. MED has a faster melting rate than HIG that closely follows the observations until the end of May. For the four years analyzed, the simulated SWE mean absolute errors are 91, 25, 20, 36, and 37 for LOW, MED, HIG, MOSN, and MFEI, respectively. MOSN has the same atmospheric forcing as MED, but neglects the liquid precipitation interception in the snowpack (with consequent refreezing and an increase of SWE). This results in an augmented sensitivity of the SWE evolution to the partitioning between liquid and solid precipitation. From 1 November to 1 March of 2006-2007, MED accumulated $186 \mathrm{~mm}$ while MOSN accumulated only $116 \mathrm{~mm}$ of water in the snowpack. The ERAI forcing has lower values of total precipitation and in particular snowfall when compared with WFC (MED versus MFEI in Table 2). This can be primarily attributed to orographic effects that are enhanced in WFC because of the higher resolution of the atmospheric model. The differences between MED and MOSN and MFEI have different causes, but lead to a similar temporal evolution of SWE in 20082009 and 2009-2010. Both simulations exhibit an underestimation of SWE throughout the cold season when compared 

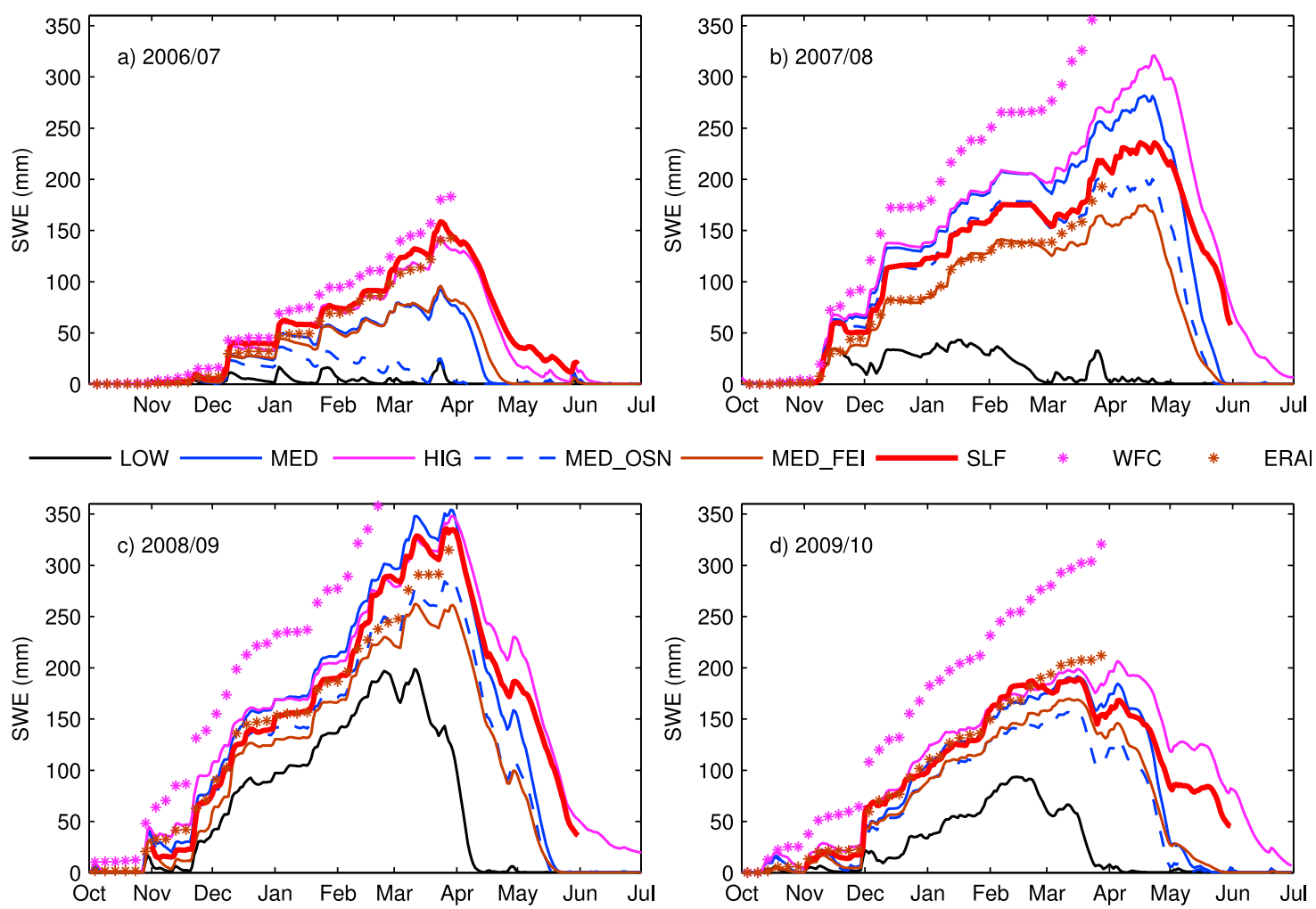

Figure 3. Mean SWE over Switzerland. Each panel presents the time series for October to June of (a) 2006-2007, (b) 2007-2008, (c) 2008-2009, and (d) 2009-2010. Simulation results are (black) LOW, (blue) MED, (magenta) HIG, (dashed blue) MOSN, and (brown) MFEI and observations from (thick red) SLF. The symbols represent the accumulated snowfall of (brown) ERAI and (magenta) WFC since 1 October of each year.

with MED. Still, the total snow ablation occurs at the same time as in MED. These results highlight the importance of both the snow scheme parameterization and the atmospheric forcing accuracy, which contribute similarly to the evolution of SWE over Switzerland.

\subsection{Snow Cover Duration in Europe}

[26] Snow cover duration is analyzed in four European regions, where model simulations are compared against two independent data sets: IMS and SNOWCLIM (Figure 4). While SWE, SCA, or SCF is precisely defined, the calculation of SCD implies the assumption of a certain threshold that defines whether snow is present or not. Moreover, the threshold can be defined for a variety of variables, such as SWE, snow depth, or SCF. In this study, SCD is derived from SCF, to allow its calculation using the IMS snow cover maps. Three thresholds were tested, $0.25,0.5$, and 0.75 . In Figure 4 the IMS estimates of SCD are presented for the threshold of 0.5 (as for the model simulations) (red line) and the uncertainty between 0.25 and 0.75 as a light red shaded area. In the Alps region the uncertainty of SCD that is due to the threshold is large while it is almost nonexistent for the other three regions. Similar behavior was found for the model simulations (not shown).

[27] In general there is a good agreement between the IMS estimates and SNOWCLIM in the four regions, except in the 2008 winter over the Alps and Scandinavia, where SNOWCLIM indicates a lower SCD than IMS does. Part of the difference between SNOWCLIM and IMS is related to the definition of SCD in SNOWCLIM (a snow depth of at least $1 \mathrm{~cm}$ ) or to missing station values. The different resolution simulations produce a similar SCD for all regions except in the Alps, with a strong underestimation by LOW during the 2006-2007 winter that is consistent with the SWE results discussed before over Switzerland (although the Alps region covers a larger area than Switzerland). In middle Europe, the SCD in 2009-2010 shows anomalous high values both in the observations and the model simulations. This finding is also documented by Seager et al. [2010], who identified snow anomalies during this winter in the Northern Hemisphere. Also, in middle and eastern Europe the MFEI shows an underestimation of the SCD,

Table 2. Accumulated Water Fluxes ( $\mathrm{mm}$ ) Over Switzerland From 1 November to 1 March in 2006-2007 and 2007-2008: Rainfall (Rainf), Intercepted Precipitation by the Snowpack (Intercept), Snowfall (Snowf), and Snowmelting (Melt)

\begin{tabular}{|c|c|c|c|c|c|c|c|c|}
\hline & \multicolumn{4}{|c|}{$2006 / 2007$} & \multicolumn{4}{|c|}{$2007 / 2008$} \\
\hline & Rainf & Intercept & Snowf $^{a}$ & Melt & Rainf & Intercept & Snowf $^{a}$ & Melt \\
\hline LOW & 256 & 36 & 74 (110) & 107 & 175 & 83 & $180(263)$ & 257 \\
\hline MED & 224 & 70 & $116(186)$ & 112 & 122 & 59 & 252 & 119 \\
\hline HIG & 210 & 59 & $122(181)$ & 80 & 110 & 36 & $260(296)$ & 97 \\
\hline MOSN & 224 & 0 & $116(116)$ & 98 & 122 & 0 & $252(252)$ & 94 \\
\hline MFEI & 219 & 57 & 98 (155) & 83 & 190 & 85 & $134(219)$ & 87 \\
\hline
\end{tabular}

${ }^{\mathrm{a}}$ The values in parentheses represent the sum of snowfall and interception. 

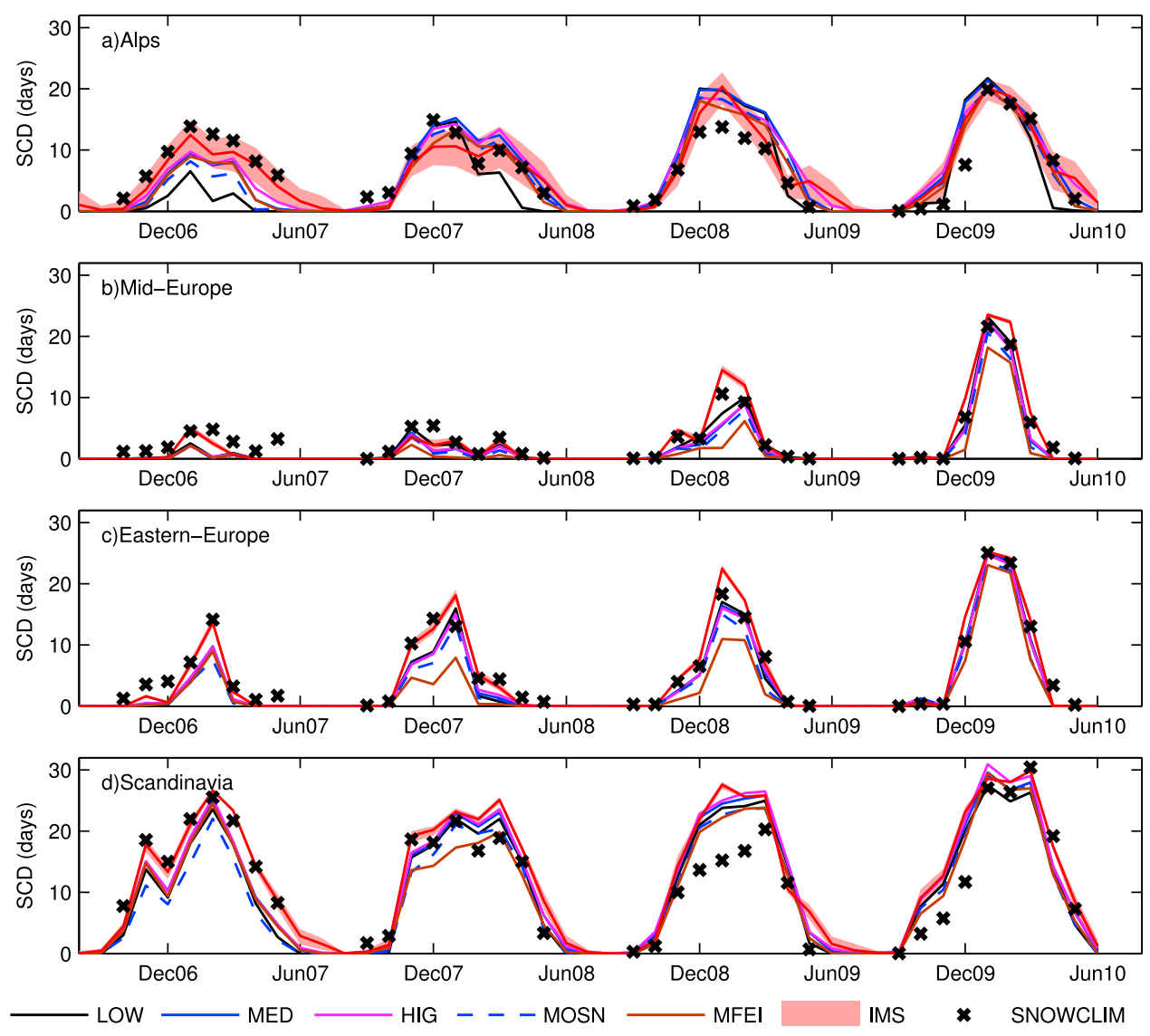

Figure 4. Time series of mean monthly snow cover duration (in days) in (a) the Alps, (b) mid-Europe, (c) eastern Europe, and (d) Scandinavia. HTESSEL simulations (black) LOW, (blue) MED, (magenta) HIG, (dashed blue) MOSN, and (brown) MFEI are compared with (black symbols) SNOWCLIM and IMS estimates. The IMS estimates represent the uncertainty of the SCD calculation using 0.25 and $0.75 \mathrm{SCF}$ for (filled solid light red) the threshold, and SCD evaluated for a (red line) 0.5 threshold.

especially during the 2007-2008 and 2008-2009 winters, that is associated with an underestimation of snowfall in ERAI when compared with the WFC. In Eastern Europe from 1 November 2007 to 1 March 2008 the WFC predicted $72 \mathrm{~mm}$ of accumulated snowfall, while ERAI predicted only $36 \mathrm{~mm}$.

\subsection{Snow-Covered Area and Fraction}

[28] The simulated snow-covered area (SCA) is compared against IMS in Figure 5 for four regions. LOW simulations systematically overestimate the SCA in the Alps during the accumulation period compared with an underestimation during the ablation period. When compared with LOW, both MED and HIG reduce the positive and negative biases during the accumulation and ablation periods, respectively. The mean absolute errors (MAEs) of SCA during spring normalized by the mean observed SCA in Table 3 illustrate the resolution impact with a reduction of $42 \%$ of the error from LOW to HIG in the Alps.

[29] In the Rocky Mountains the SCA is generally underestimated (Figure 5c), with a reduction of the bias with increased resolution, whereas for other flat terrain regions, such as ME, EE, SC, CE, and CC, the different resolutions show a limited impact (see Table 3). The SCA biases in the
Northern Hemisphere depict the reduced impact of horizontal resolution on a global scale, showing almost overlapping curves in Figure 5d.

[30] While the impact of the resolution of the land surface model is mainly restricted to complex terrain regions, the old snow physics (MOSN) and ERAI atmospheric forcing (MFEI) have a noticeable impact on the SCA. The spring biases in Table 3 show that MFEI has larger errors than MED, which is mainly due to a systematic underestimation of the SCA (as shown for the NH in Figure 5d) in all regions, except the Alps and the Himalayas. This is mainly due to the atmospheric forcing, with an underestimation of snowfall by ERAI when compared with the WFC. For example, the accumulated snowfall amounts to 86 and $63 \mathrm{~mm}$ in the WFC and ERAI, respectively, averaged over the NH from 1 November 2007 to 1 March 2008. One of the reasons for these differences is the higher spatial resolution of the WFC, with an improved representation of orographic features and the partitioning between liquid and solid precipitation. The effects of the old snow physics, forced with the WFC, tend to be similar to those of the simulations forced with ERAI. Generally, MOSN is closer to MED than MFEI, but is subject to a similar SCA underestimation. This is primarily due to the lack of rainfall interception in the snowpack and 

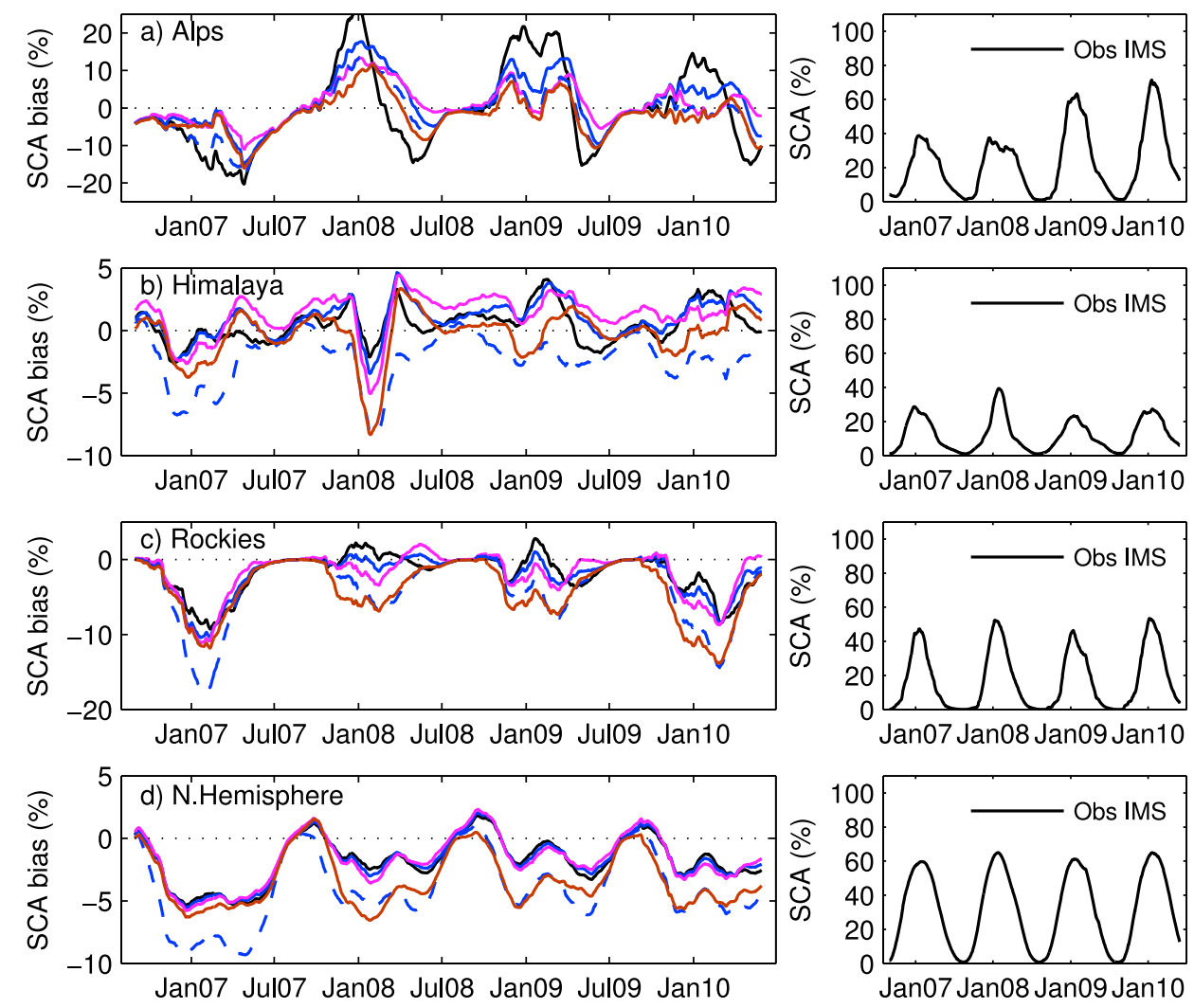

$\longrightarrow$ LOW MED $\longrightarrow$ HIG - - - MED_OSN MED_FEI

Figure 5. (left) Bias of simulated snow-covered area (SCA) (simulations, IMS) in (a) the Alps, (b) the Himalayas, (c) the Rockies, and (d) Northern Hemisphere; (right) associated IMS observations. Both simulated biases and observed SCA are normalized by the total area of each region. The vertical axes represent the bias, or observed, SCA in terms of percentage of the total area of each region.

early melting associated with an underestimation of surface albedo (see Dutra et al. [2010a] for a detailed evaluation of the NEW and old snow schemes). These results show that the underestimation of snowfall in ERAI, when compared with the WFC, has an impact similar to neglecting the interception of rainfall in the snowpack in MOSN, which was already discussed in the previous section. The magnitude of SCA biases in Scandinavia is comparable to other areas with a lower forest fraction, suggesting that the treatment of exposed versus shaded snow in HTESSEL does not contribute considerably to the errors.

[31] The relation between resolution, snow physics, and atmospheric forcing in simulating SCA is consistently observed in all regions except the Alps and the Himalayas. In the Alps, MOSN has a better performance than MED. In the Himalayas the increased horizontal resolution increases the SCA MAE in spring with an overestimation of SCA in HIG compared with LOW (Figure 5b). SCA is one of the most common measures used to validate simulations of snow by land surface models or climate models [e.g., Roesch, 2006; Sheffield et al., 2003]. It is an integral quantity with the shortcomings of hiding compensating errors in the spatial distribution of snow cover, i.e., SCA can be close to the observations in a certain region but geographically misplaced within that region. The spatial correlation (or pattern correlation coefficient) provides a measure of the degree of spatial coherence between simulated and observed SCF. The Pearson correlation is calculated for each month between HTESSEL simulations and observations of SCF at HIGR for all grid points in each region.

[32] Figure 6 displays the temporal evolution of the spatial correlation between monthly simulated and observed SCFs for the same regions as in Figure 5, and Table 4 summarizes the mean correlation values averaged for all spring months. The time series show a pronounced seasonal cycle in all regions, with higher values in the cold season peak and a reduction as we move to summer. This measure is sensitive to the snow cover extent in the region. In the Himalayas, the correlations increase with increasing resolution while SCA

Table 3. Mean Absolute Error (MAE) of Snow-Covered Area in Spring (March-May 2007-2010) for Each Simulation and Each Analysis Region $^{\mathrm{a}}$

\begin{tabular}{lccccccccc}
\hline & AL & ME & EE & SC & HY & RK & CE & CC & NH \\
\hline LOW & 61 & 46 & 32 & 17 & 16 & 27 & 5 & 14 & 8 \\
MED & 38 & 48 & 34 & 13 & 24 & 21 & 6 & 15 & 7 \\
HIG & 26 & 46 & 33 & 14 & 28 & 18 & 6 & 15 & 7 \\
MOSN & 28 & 57 & 47 & 23 & 22 & 35 & 12 & 22 & 17 \\
MFEI & 35 & 65 & 48 & 20 & 19 & 31 & 8 & 19 & 12
\end{tabular}

${ }^{\mathrm{a}}$ MAE was normalized by the mean observed snow-covered area during spring in each region. 

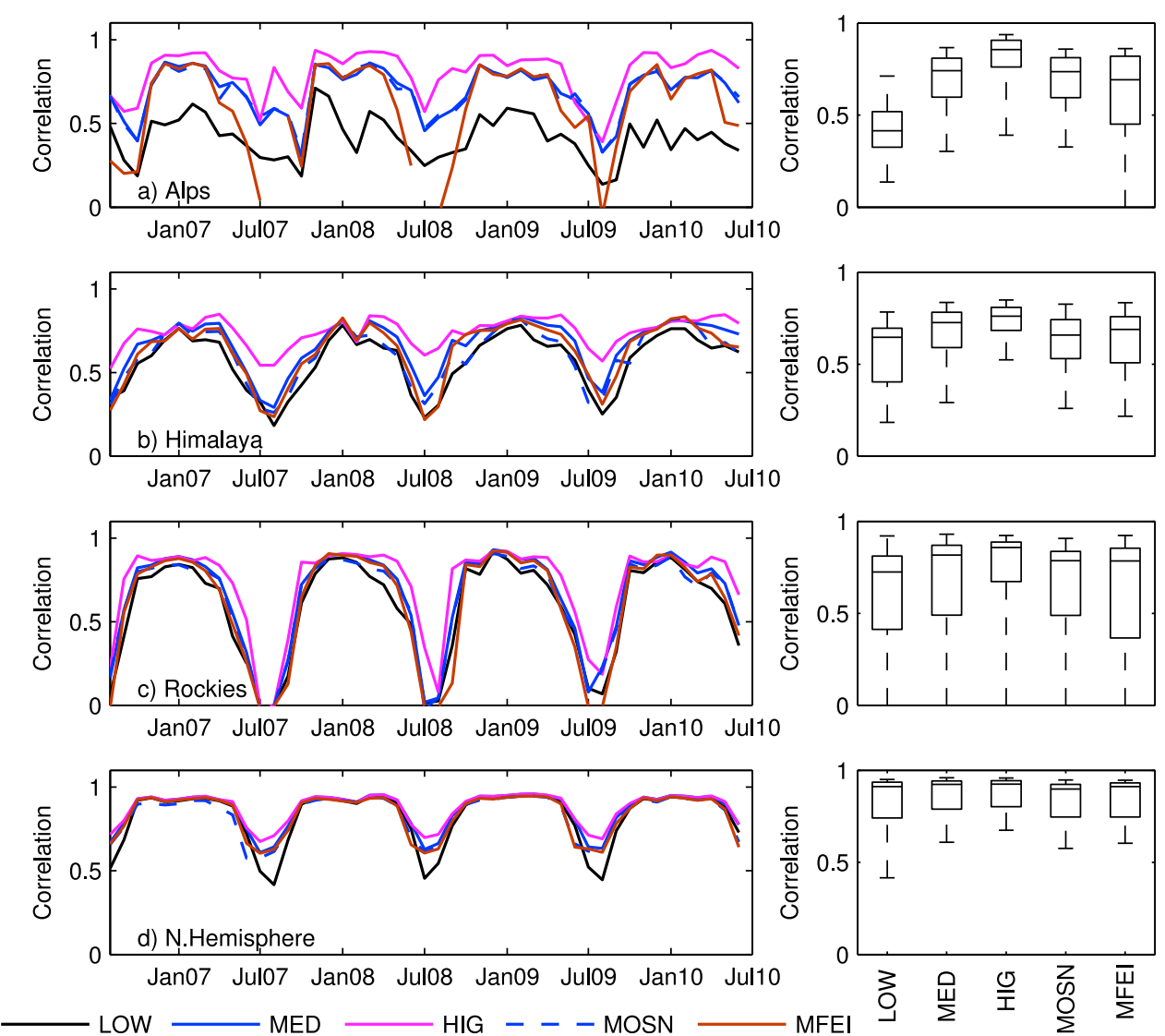

Figure 6. (left) Temporal evolution of the spatial correlation (spatial Pearson correlation coefficient) between monthly simulated and observed snow cover fraction in (a) the Alps, (b) the Himalayas, (c) the Rockies, and (d) and the Northern Hemisphere. (right) For each region, the box plot summaries of the pattern correlation coefficients. The boxes have horizontal lines at the lower quartile, median, and upper quartile, and the whiskers (vertical lines) extend from the end of each box to the maximum and minimum.

MAEs do not. This is due to compensating negative and positive SCF biases in LOW (compare Figures 7a and 7c), resulting in lower SCA errors than in HIG. These findings illustrate the shortcomings of using SCA as a validation measure by itself and the benefits of complementing the analysis with the spatial correlation. In the Alps, MOSN and MED have similar spatial correlations, whereas SCA shows an improved performance of MOSN when compared with MED. As for SCA, the spatial correlations show a reduced impact of resolution in flat areas (SC, CE, and CC) and in the Northern Hemisphere as a whole, whereas in mountain regions ( $\mathrm{AL}, \mathrm{HY}$, and $\mathrm{RK}$ ) there is a consistent improvement with increased resolution. The smaller regions of middle and eastern Europe exhibit an increase of the spatial correlation with increased resolution, which was not the case for SCA. However, the spatial correlations are lower than for the remaining regions. A plausible reason for this is the low snow cover extent in areas where a relatively small error in simulating SCF can lead to a very poor spatial correlation. Snow physics and atmospheric forcing do not show the large impacts found for SCA; nonetheless the deficiencies in MFEI and MOSN when compared with MED are still evident.

[33] A spatial overview of the results discussed in this section is presented in Figure 7 with the representation of the mean spring biases of simulated snow cover fraction in Eurasia and the associated snow cover map from IMS. The snowline (snow fraction $=0.5$ ) in spring (Figure 7f) is located around $55^{\circ} \mathrm{N}$ in Eurasia with a southward displacement as we move from west to east. Several orographic features with increased snow cover can be observed, such as the Alpine region, the Caucasus Mountains, the Ural Mountains, the Himalaya range, and the Altai Mountains, among others. In general, all simulations (Figures 7a-7e) have limitations in representing snow cover in mountain regions, especially in the Himalayas. In the Alpine region there is an overestimation along the northern and southern

Table 4. Spatial Correlation (Pattern Correlation Coefficient) Between Monthly Simulated and Observed Snow Cover Fraction in Each Analysis Region Averaged for all Spring Months (MarchMay 2007-2010)

\begin{tabular}{lccccccccc}
\hline & AL & ME & EE & SC & HY & RK & CE & CC & NH \\
\hline LOW & 0.46 & 0.20 & 0.35 & 0.83 & 0.66 & 0.67 & 0.85 & 0.85 & 0.92 \\
MED & 0.77 & 0.28 & 0.43 & 0.88 & 0.77 & 0.77 & 0.88 & 0.87 & 0.93 \\
HIG & 0.89 & 0.43 & 0.76 & 0.89 & 0.82 & 0.85 & 0.88 & 0.87 & 0.94 \\
MOSN & 0.76 & 0.28 & 0.42 & 0.79 & 0.69 & 0.74 & 0.84 & 0.81 & 0.91 \\
MFEI & 0.71 & 0.26 & 0.30 & 0.84 & 0.73 & 0.73 & 0.86 & 0.84 & 0.92
\end{tabular}


a)LOW-IMS

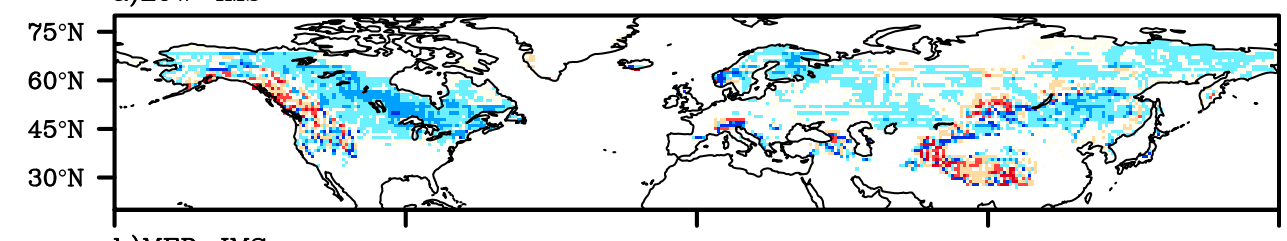

b)MED-IMS

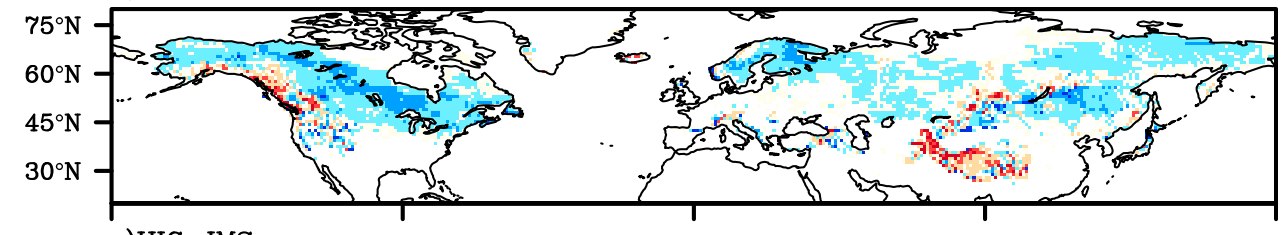

c)HIG-IMS

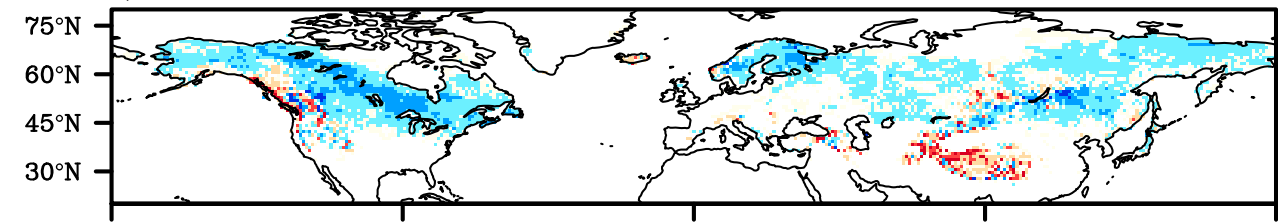

d)MOSN-IMS

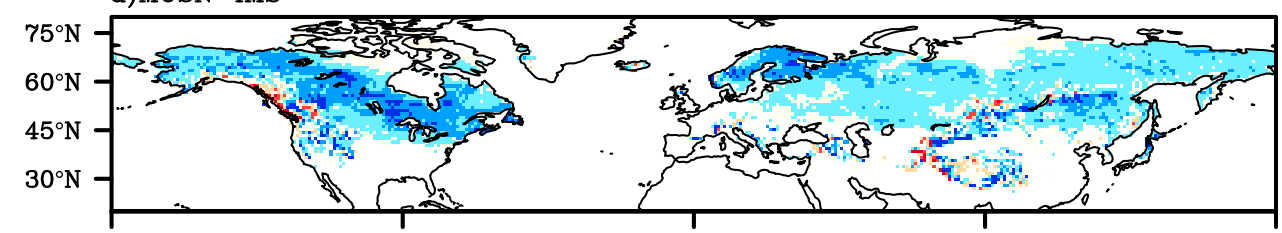

e)MFEI-IMS

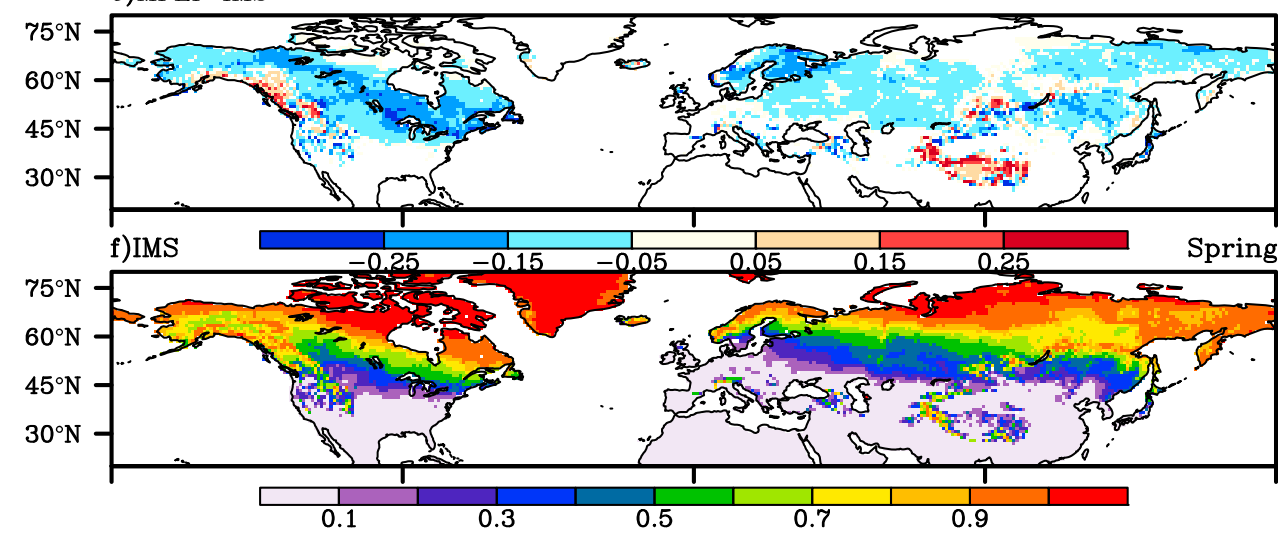

Figure 7. Mean spring (March-May 2007-2010) simulated snow cover fraction differences with respect to IMS: (a) LOW, (b) MED, (c) HIG, (d) MOSN, (e) MFEI, and (f) mean spring snow cover. Note the different color scales between $7 \mathrm{a}-7 \mathrm{e}$ and $7 \mathrm{f}$.

rims of the mountain range and an underestimation along the Alpine ridge in LOW that is partially reduced in MED and almost nonexistent in HIG. The different resolutions show similar patterns of early melting throughout the snowline, with a remarkable performance over the Ural Mountains. The early melting is more pronounced in MFEI than in MED, both in intensity and spatial spread, whereas MOSN shows even larger biases, especially in eastern Scandinavia.

\subsection{Surface Albedo}

[34] The evaluation of surface albedo complements the above results since surface albedo gives a radiative balance perspective of snow cover presence over land. Time series of simulated and MODIS surface albedo in several regions are presented in Figure 8. As reported for the IMS SCA, the MODIS albedo shows a distinct increase of surface albedo over the Alps in the 2009 and 2010 winter seasons. MidEurope and eastern Europe also had a high snow cover extent and duration during the 2010 winter (see Figure 4), which is also confirmed by the MODIS albedo (not shown). The 2008 winter in the Himalayas is also characterized by a higher surface albedo as well as by a high IMS SCA. Although these three examples are solely based on a visual inspection of the time series, they illustrate the coherency between the two independent data sets. However, the relation among SWE (the prognostic quantity in the model), SCF, and surface albedo is still a research subject in the land surface modeling community. The model surface albedo 


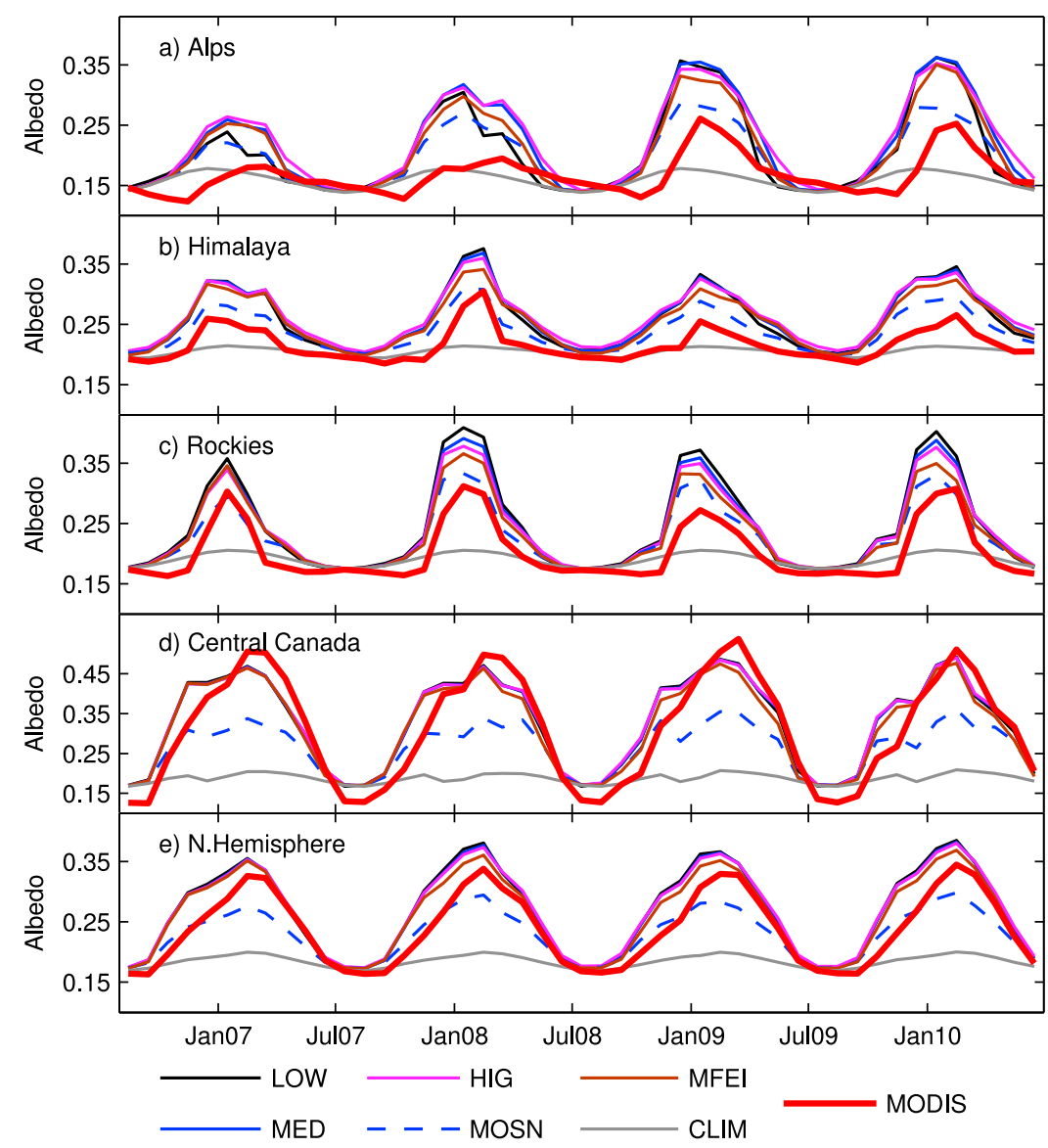

Figure 8. Mean monthly simulated surface albedo in (a) the Alps, (b) the Himalayas, (c) the Rockies, (d), central Canada, and (e) and Northern Hemisphere. Simulation results include (black) LOW, (blue) MED, (magenta) HIG, (dashed blue) MOSN, and (brown) MFEI. Observations from (thick red) MODIS represent monthly means over each region. The simulations were spatially averaged using only grid points where MODIS was available to ensure a fair comparison. The model's background climatology (snow free) for each region is also represented as (gray) CLIM.

background (snow-free) climatology, identical in all simulations, is also represented in Figure 8. Comparing the background climatology with the simulations, or MODIS, it is possible to infer that the annual cycle of surface albedo, on the hemispheric scale, is mainly driven by snow cover presence. This shows the importance of a correct representation of snow cover and its relation to surface albedo in land surface models.

[35] In the three mountainous regions represented in Figure 8 (Alps, Rockies, and Himalayas), there is a pronounced overestimation of surface albedo throughout the snow-covered period. Such a signal is not found in SCA for the mentioned regions. In central Canada and the Northern Hemisphere, all simulations applying the NEW snow scheme show an overestimation of surface albedo during the accumulation period that is reduced (almost nonexistent) during the ablation period. The different resolutions and ERAI forcing have a small impact on surface albedo. In contrast, using the old snow physics leads to large differences in the remaining simulations in terms of a reduction of the surface albedo throughout the cold season.
[36] The mean surface albedo maps in spring from MODIS and the respective simulation differences are shown in Figure 9. The presence of snow in spring has a distinct signal on the MODIS surface albedo (Figure 9f). All simulations show an overestimation in two distinct areas: the Himalayan mountain range and the central Siberian Plateau. This signal is present in snow cover extent only in the Himalayas. The bias over the Siberian Plateau is not associated with snow cover extent but rather with snow albedo. Furthermore, the overestimation is larger in all simulations performed with the NEW snow scheme (e.g., MED) when compared with MOSN. On the other hand, MOSN presents a spatially spread pattern of surface albedo underestimation poleward of $60^{\circ} \mathrm{N}$. This bias was addressed in the revision of the old snow scheme and is partially reduced with the NEW snow scheme. As for snow cover fraction, the horizontal resolution does not have a significant impact on surface albedo. ERAI forcing shows a significant impact on snow cover, but the impact on surface albedo is negligible (MED versus MFEI in Figures 9b and 9e). The comparison of the model simulations against MODIS also highlights 
a)LOW-MODIS

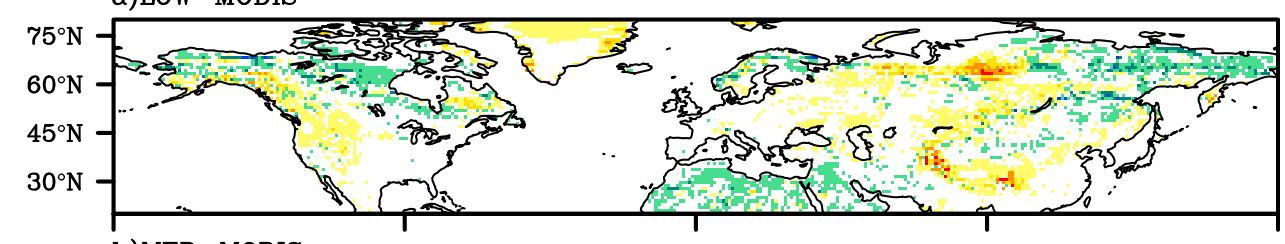

b)MED-MODIS

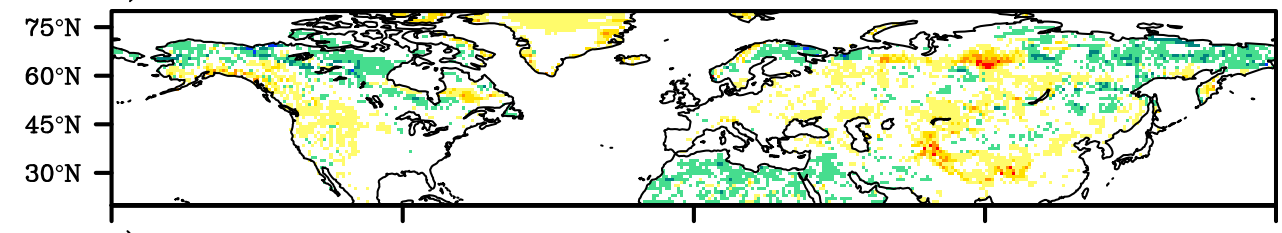

c)HIG-MODIS

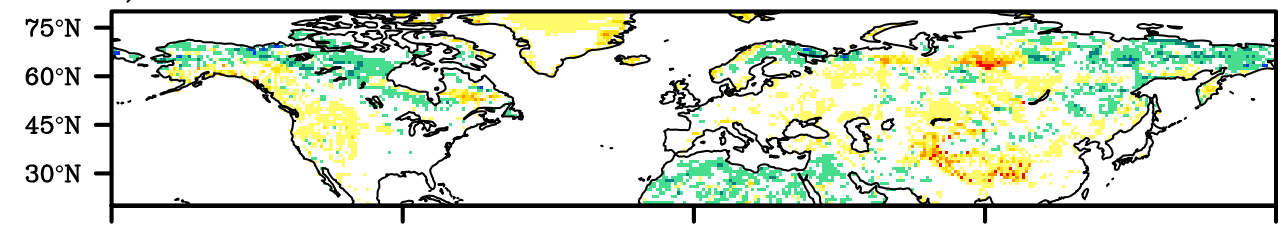

d)MOSN-MODIS

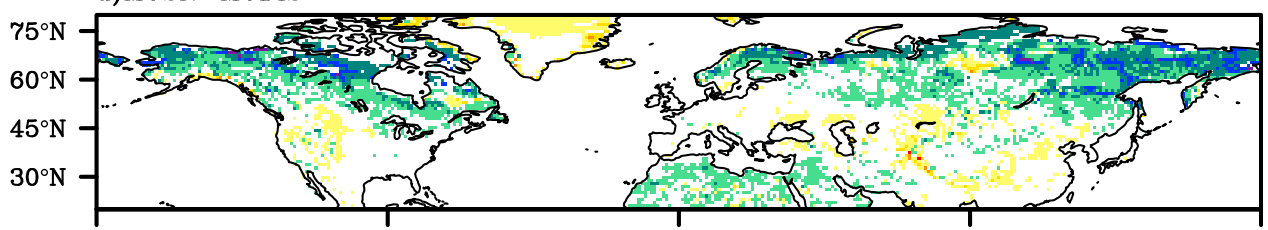

e)MFEI-MODIS

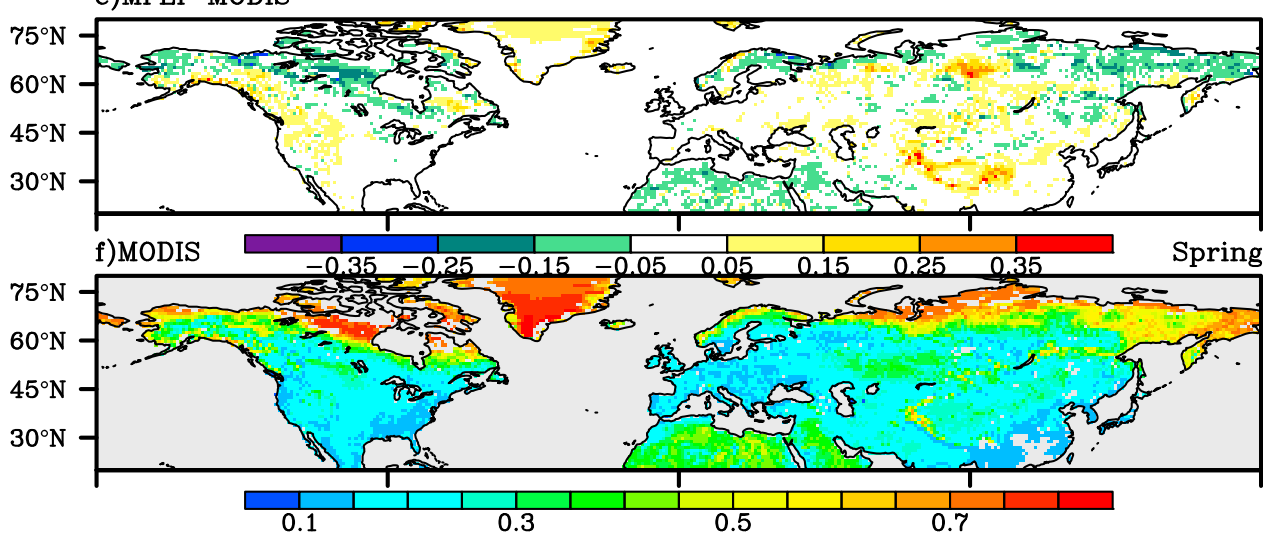

Figure 9. Mean spring (March-May 2007-2010) simulated surface albedo differences with respect to MODIS: (a) LOW, (b) MED, (c) HIG, (d) MOSN, (e) MFEI and (f) MODIS mean spring snow cover. Note the different color scales between $9 \mathrm{a}-9 \mathrm{e}$ and $9 \mathrm{f}$.

some differences in North Africa that are associated with the background climatology used in HTESSEL. In 2007, the background albedo of the ECMWF integrated forecast system changed to a climatology derived from MODIS, discriminating between direct and diffuse and near-infrared and visible surface albedos (in snow-free conditions). The offline simulations with HTESSEL still use the old background climatology (described in section 2.1) since the usual atmospheric forcings (including ERAI and WFC) provide only the full (broadband) solar radiation downward flux. In summary, the differences found in the simulated surface albedo when compared with MODIS are due to three main factors: (1) deficiencies of the simulated snow cover fraction, (i2) deficiencies of the simulated snow albedo, and
(3) deficiencies of the snow-free background climatology prescribed in HTESSEL.

\section{Conclusions}

[37] This study presents an assessment of three different factors controlling off-line simulations of snow cover in the LSM HTESSEL. The assessment was carried out by comparing the simulations against different observational data sets. Over the topographically structured area of Switzerland, the simulations of snow water equivalent (SWE) are sensitive to the horizontal resolution. Pronounced differences were found between the low and intermediate resolutions, whereas the latter showed a behavior similar to that 
of the high-resolution simulation, except during the final ablation period. The underestimation of SWE by the lowresolution simulation is due to the underprediction of snowfall, resulting from forcing interpolation, and due to higher melting rates when compared with the higher-resolution runs. The simulations forced with ERAI and forced with WFC running with the old snow physics underestimate SWE but show a similar SWE temporal evolution. ERAI underpredicts snowfall (when compared with WFC) while the old snow physics neglects the interception of rainfall in the snowpack. While the resolution impact is significant for the runs at 200 and $80 \mathrm{~km}$, at $80 \mathrm{~km}$ the atmospheric forcing accuracy and snow scheme parameterization contribute almost equally to the evolution of SWE over Switzerland, more than increasing the resolution to $25 \mathrm{~km}$.

[38] Snow cover duration (SCD) analyzed in four European regions shows a reasonable agreement between the IMS estimates and SNOWCLIM, which represent two independent data sets (remote sensing based and station based). The evaluation of SCD is constrained by the definition of the threshold for the presence of snow. However, for snow cover fraction (SCF) the associated uncertainty of using values between 0.25 and 0.75 is mainly restricted to the Alps region, where all simulations, except at low resolution, are similar to IMS and SNOWCLIM. The simulation forced by ERAI tends to underestimate SCD, especially in middle and eastern Europe. The analysis suggests that a possible cause is the underprediction of snowfall in ERAI when compared with WFC. From October 2007 onward, the ECMWF deterministic forecast predicts more snowfall than ERAI (see Figure 2) because of a change in the atmospheric model, which led to an improvement of SCA simulations by WFC when compared with ERAI. During the 2006-2007 winter, both MED and MFEI display similar SCA underestimations (see Figure 5) on a hemispheric scale, while from 2007-2008 onward MED improved.

[39] Although snow-covered area (SCA) is commonly used as a validation metric, it is shown that it should be used in conjunction with the SCF spatial correlation. While SCA can hide compensating errors, the spatial correlation reflects the spatial coherency of the snow-covered versus snow-free areas in a certain region in different data sets. This is the case in the Himalayas, where the SCA error during spring increases in the higher-resolution run. However, the spatial correlation analysis shows that the high-resolution simulation had a better spatial coherency with the IMS than with the lower-resolution simulations. In general, increased resolution improves SCA and spatial correlations in complex terrain areas, such as the Alps, Himalayas, and Rockies, while in the remaining regions, including the Northern Hemisphere as a whole, the impact of resolution is reduced. Finally, the surface albedo evaluation against MODIS does not show a strong dependence on horizontal resolution or atmospheric forcing, but rather on the model physics. However, the current model simulation setup does not allow unambiguous identification of the processes that are more important among the set of surface albedo changes. The evaluation of surface albedo highlights the importance of a correct representation of snow cover in the model, since on a hemispheric scale the annual cycle of surface albedo is mainly driven by the presence of snow.
[40] This work identified some deficiencies of the NEW snow scheme of HTESSEL concerning the representation of snow processes in mountainous regions associated with both the snowpack physics and the surface albedo. They can be primarily attributed to missing processes associated with subgrid-scale variability that is not accounted for in HTESSEL (for example, shading vegetation effects, blowing snow, distribution of snow mass over complex topography and its relation with snow cover). Parajka et al. [2010] also found that simulations of snow cover and depth by a land surface model had the poorest performance in regions of significant topographic heterogeneity. The authors suggest that the most promising additional model developments should be directed toward computationally efficient representations of subgrid topography.

[41] The horizontal resolution proved to play an important role in simulating snow cover in complex terrain regions, while its impact on flat terrain regions is reduced. In the latter regions, the atmospheric forcing accuracy and model physics play a more important role. These results are model dependent, and their generalization is not certain, especially concerning the model physics. However, they show that developments in land surface models are strongly dependent on the available forcing and validation data set quality. In this study, horizontal resolution was assessed by forcing the model with a high-quality atmospheric data set originally available at high resolution. The simulation setup framework presented in this paper can also be applied to investigate other land-atmosphere processes, especially alternative approaches to describe land surface subgrid-scale variability, which is a critical point in climate models.

[42] Acknowledgments. The National Snow and Ice Data Center is acknowledged for providing the IMS snow cover data. We also thank the MODIS albedo science team and the Land Processes Distributed Active Archive Center (LP DAAC) for providing the MCD43C albedo data. Part of the ground observations on snow depth were kindly provided by the Swiss Federal Office of Meteorology and Climatology MeteoSwiss. Deutscher Wetterdienst (DWD) provided the SNOWCLIM gridded data. We would like to thank Anton Beljaars and Richard Forbes for their comments on the ECMWF atmospheric forcing, and the anonymous reviewers for their thoughtful comments. This work was supported by the Portuguese Foundation for Science and Technology (FCT) under project AMIC PTDC/ AAC-CLI/109030/2008, cofinanced by the European Union under program FEDER. E. Dutra acknowledges the financial support of FCT under grant $\mathrm{SFRH} / \mathrm{BD} / 35789 / 2007$.

\section{References}

Armstrong, R. L., and E. Brun (2008), Snow and Climate. Physical Processes, Surface Energy Exchange and Modeling, Cambridge Univ. Press, New York.

Balsamo, G., P. Viterbo, A. Beljaars, B. Van den Hurk, A. K. Betts, and K. Scipal (2009), A revised hydrology for the ECMWF model: Verification from field site to terrestrial water storage and impact in the Integrated Forecast System, J. Hydrometeorol., 10(3), 623-643 doi:610.1175/ 2008JHM1068.1171.

Barnett, T. P., J. C. Adam, and D. P. Lettenmaier (2005), Potential impacts of a warming climate on water availability in snow-dominated regions, Nature, 438(7066), 303-309, doi:10.1038/nature04141.

Beniston, M., B. Uhlmann, S. Goyette, and J. I. Lopez-Moreno (2010), Will snow-abundant winters still exist in the Swiss Alps in an enhanced greenhouse climate?, Int. J. Climatol., 31, 1257-1263, doi:10.1002/ joc. 2151 .

Boone, A., et al. (2004), The Rhone-aggregation land surface scheme intercomparison project: An overview, J. Clim., 17(1), 187-208, doi:10.1175/ 1520-0442(2004)017<0187:TRLSSI $>2.0$. CO;2

Bowling, L. C., et al. (2003), Simulation of high-latitude hydrological processes in the Torne-Kalix basin: PILPS phase 2(e): 1: Experiment 
description and summary intercomparisons, Global Planet. Change, 38(1-2), 1-30, doi:10.1016/S0921-8181(03)00003-1.

Brown, R., C. Derksen, and L. Wang (2007), Assessment of spring snow cover duration variability over northern Canada from satellite datasets, Remote Sens. Environ., 111(2-3), 367-381, doi:10.1016/j.rse.2006.09.035.

Brubaker, K. L., R. T. Pinker, and E. Deviatova (2005), Evaluation and comparison of MODIS and IMS snow-cover estimates for the continental United States using station data, J. Hydrometeorol., 6(6), 1002-1017, doi:10.1175/JHM447.1.

Brun, E., P. David, M. Sudul, and G. Brunot (1992), A numerical-model to simulate snow-cover stratigraphy for operational avalanche forecasting, J. Glaciol., 38(128), 13-22.

Carrera, M. L., S. Bélair, V. Fortin, B. Bilodeau, D. Charpentier, and I. Doré (2010), Evaluation of snowpack simulations over the Canadian Rockies with an experimental hydrometeorological modeling system, J. Hydrometeorol., 11(5), 1123-1140, doi:10.1175/2010JHM1274.1.

Christensen, J. H., and O. B. Christensen (2007), A summary of the PRUDENCE model projections of changes in European climate by the end of this century, Clim. Change, 81, 7-30, doi:10.1007/s10584-0069210-7.

Dee, D. P., et al. (2011), The ERA-Interim reanalysis: Configuration and performance of the data assimilation system, Q. J. R. Meteorol. Soc., 137(656), 553-597, doi:10.1002/qj.828.

Drusch, M., D. Vasiljevic, and P. Viterbo (2004), ECMWF's global snow analysis: Assessment and revision based on satellite observations, J. Appl. Meteorol., 43(9), 1282-1294, doi:10.1175/1520-0450(2004)043<1282 EGSAAA $>2.0 . \mathrm{CO} ; 2$

Dutra, E., G. Balsamo, P. Viterbo, P. M. A. Miranda, A. Beljaars, C. Schar, and K. Elder (2010a), An improved snow scheme for the ECMWF land surface model: Description and offline validation, J. Hydrometeorol., 11(4), 899-916, doi:10.1175/2010JHM1249.1.

Dutra, E., V. M. Stepanenko, G. Balsamo, P. Viterbo, P. M. A. Miranda, D. Mironov, and C. Schar (2010b), An offline study of the impact of lakes on the performance of the ECMWF surface scheme, Boreal Environ. Res., 15(2), 100-112.

Fletcher, C. G., S. C. Hardiman, P. J. Kushner, and J. Cohen (2009), The dynamical response to snow cover perturbations in a large ensemble of atmospheric GCM integrations, J. Clim., 22(5), 1208-1222, doi:10.1175/2008JCLI2505.1.

Foppa, N., A. Stoffel, and R. Meister (2007), Synergy of in situ and space borne observation for snow depth mapping in the Swiss Alps, Int. J. Appl. Earth Observ. Geoinf., 9(3), 294-310, doi:10.1016/j.jag.2006.10. 001 .

Giorgi, F., R. Francisco, and J. Pal (2003), Effects of a subgrid-scale topography and land use scheme on the simulation of surface climate and hydrology. Part I: Effects of temperature and water vapor disaggregation, J. Hydrometeorol., 4(2), 317-333, doi:10.1175/1525-7541(2003)4<317: EOASTA $>2.0 . \mathrm{CO} ; 2$.

Hazeleger, W., et al. (2010), EC-Earth: A seamless Earth-system prediction approach in action, Bull. Am. Meteorol. Soc., 91(10), 1357-1363, doi:10.1175/2010BAMS2877.1

Helfrich, S. R., D. McNamara, B. H. Ramsay, T. Baldwin, and T. Kasheta (2007), Enhancements to, and forthcoming developments in the Interactive Multisensor Snow and Ice Mapping System (IMS), Hydrol. Processes, 21(12), 1576-1586, doi:10.1002/hyp.6720.

Hogewind, F., and P. Bissolli (2011), Operational maps of monthly mean temperature for WMO Region VI (Europe and Middle East), Idojaras, 115(1-2), 31-49.

Huffman, G. J., R. F. Adler, D. T. Bolvin, and G. Gu (2009), Improving the global precipitation record: GPCP Version 2.1, Geophys. Res. Lett., 36, L17808, doi:10.1029/2009GL040000.

Im, E. S., E. Coppola, F. Giorgi, and X. Bi (2010), Validation of a highresolution regional climate model for the Alpine region and effects of a subgrid-scale topography and land use representation, J. Clim., 23(7), 1854-1873, doi:10.1175/2009JCLI3262.1.

Jonas, T., C. Marty, and J. Magnusson (2009), Estimating the snow water equivalent from snow depth measurements in the Swiss Alps, J. Hydrol., 378(1-2), 161-167, doi:10.1016/j.jhydrol.2009.09.021.

Jung, T., et al. (2010), The ECMWF model climate: Recent progress through improved physical parametrizations, Q. J. R. Meteorol. Soc., 136(650), 1145-1160, doi:10.1002/qj.634.

Kotlarski, S., F. Paul, and D. Jacob (2010), Forcing a distributed glacier mass balance model with the regional climate model REMO. Part I: Climate model evaluation, J. Clim., 23(6), 1589-1606, doi: 10.1175/ 2009JCLI2711.1.

Laternser, M., and M. Schneebeli (2003), Long-term snow climate trends of the Swiss Alps (1931-99), Int. J. Climatol., 23(7), 733-750, doi:10.1002/joc.912.
Liston, G. E. (2004), Representing subgrid snow cover heterogeneities in regional and global models, J. Clim., 17(6), 1381-1397, doi:10.1175/ 1520-0442(2004)017<1381:RSSCHI $>2.0$.CO;2.

Livneh, B., Y. L. Xia, K. E. Mitchell, M. B. Ek, and D. P. Lettenmaier (2010), Noah LSM snow model diagnostics and enhancements, J. Hydrometeorol., 11(3), 721-738, doi:10.1175/2009JHM1174.1.

Los, S. O., et al. (2000), A global 9-yr biophysical land surface dataset from NOAA AVHRR data, J. Hydrometeorol., 1(2), 183-199, doi:10.1175/1525-7541(2000)001<0183:AGYBLS $>2.0$. CO;2.

Loveland, T. R., B. C. Reed, J. F. Brown, D. O. Ohlen, Z. Zhu, L. Yang, and J. W. Merchant (2000), Development of a global land cover characteristics database and IGBP DISCover from $1 \mathrm{~km}$ AVHRR data, Int. J. Remote Sens., 21(6), 1303-1330, doi:10.1080/014311600210191.

Moody, E. G., M. D. King, C. B. Schaaf, D. K. Hall, and S. Platnick (2007), Northern Hemisphere five-year average (2000-2004) spectral albedos of surfaces in the presence of snow: Statistics computed from Terra MODIS land products, Remote Sens. Environ., 111(2-3), 337-345, doi:10.1016/j.rse.2007.03.026

Pappenberger, F., H. L. Cloke, G. Balsamo, T. Ngo-Duc, and T. Oki (2010), Global runoff routing with the hydrological component of the ECMWF NWP system, Int. J. Climatol., 30, 2155-2174, doi:10.1002/ joc. 2028 .

Parajka, J., S. Dadson, T. Lafon, and R. Essery (2010), Evaluation of snow cover and depth simulated by a land surface model using detailed regional snow observations from Austria, J. Geophys. Res., 115, D24117, doi:10.1029/2010JD014086.

Ramsay, B. H. (1998), The interactive multisensor snow and ice mapping system, Hydrol. Processes, 12(10-11), 1537-1546, doi:10.1002/(SICI) 1099-1085(199808/09)12:10/11<1537::AID-HYP679>3.0.CO;2-A

Rauscher, S. A., E. Coppola, C. Piani, and F. Giorgi (2010), Resolution effects on regional climate model simulations of seasonal precipitation over Europe, Clim. Dyn., 35(4), 685-711, doi:10.1007/s00382-0090607-7.

Richardson, D. S., J. Bidlot, L. Ferranti, A. Ghelli, C. Gibert, T. Hewson, M. Janousek, F. Prates, and F. Vitart (2009), Verification statistics and evaluations of ECMWF forecasts in 2008-2009, ECMWF Tech. Memo. 606, 45 pp., ECMWF, Reading, U. K

Roesch, A. (2006), Evaluation of surface albedo and snow cover in AR4 coupled climate models, J. Geophys. Res., 111, D15111, doi:10.1029/ 2005JD006473.

Rutter, N., et al. (2009), Evaluation of forest snow processes models (SnowMIP2), J. Geophys. Res., 114, D06111, doi:10.1029/2008JD011063. Salomon, J. G., C. B. Schaaf, A. H. Strahler, F. Gao, and Y. F. Jin (2006), Validation of the MODIS bidirectional reflectance distribution function and albedo retrievals using combined observations from the Aqua and Terra platforms, IEEE Trans. Geosci. Remote Sens., 44(6), 1555-1565, doi:10.1109/TGRS.2006.871564.

Schär, C., L. Vasilina, F. Pertziger, and S. Dirren (2004), Seasonal runoff forecasting using precipitation from meteorological data assimilation systems, J. Hydrometeorol., 5(5), 959-973, doi: 10.1175/1525-7541(2004) $005<0959$ :SRFUPF $>2.0 . \mathrm{CO} ; 2$.

Seager, R., Y. Kushnir, J. Nakamura, M. Ting, and N. Naik (2010), Northern Hemisphere winter snow anomalies: ENSO, NAO and the winter of 2009/10, Geophys. Res. Lett., 37, L14703, doi:10.1029/2010GL043830.

Sellers, P. J., S. O. Los, C. J. Tucker, C. O. Justice, D. A. Dazlich, G. J. Collatz, and D. A. Randall (1996), A revised land surface parameterization (SiB2) for atmospheric GCMs. Part II. The generation of global fields of terrestrial biophysical parameters from satellite data, J. Clim., 9(4), 706-737, doi:10.1175/1520-0442(1996)009<0706:ARLSPF $>2.0$. $\mathrm{CO} ; 2$.

Sheffield, J., et al. (2003), Snow process modeling in the North American Land Data Assimilation System (NLDAS): 1. Evaluation of modelsimulated snow cover extent, J. Geophys. Res., 108(D22), 8849, doi:10.1029/2002JD003274.

Stroeve, J., J. E. Box, F. Gao, S. L. Liang, A. Nolin, and C. Schaaf (2005), Accuracy assessment of the MODIS 16-day albedo product for snow: Comparisons with Greenland in situ measurements, Remote Sens. Environ., 94(1), 46-60, doi:10.1016/j.rse.2004.09.001

Viterbo, P., A. Beljaars, J. F. Mahfouf, and J. Teixeira (1999), The representation of soil moisture freezing and its impact on the stable boundary layer, O. J. R. Meteorol. Soc., 125(559), 2401-2426, doi:10.1002/ qj.49712555904.

Wang, Z., and X. B. Zeng (2010), Evaluation of snow albedo in land models for weather and climate studies, J. Appl. Meteorol. Climatol., 49(3), 363-380, doi:10.1175/2009JAMC2134.1

Wang, Z., X. Zeng, and M. Decker (2010), Improving snow processes in the Noah land model, J. Geophys. Res., 115, D20108, doi:10.1029/ 2009JD013761. 
Wild, M., A. Ohmura, H. Gilgen, and E. Roeckner (1995), Validation of general-circulation model radiative fluxes using surface observations, J. Clim., 8(5), 1309-1324, doi:10.1175/1520-0442(1995)008<1309: VOGCMR $>2.0 . \mathrm{CO} ; 2$.

Zhou, L., et al. (2003), Comparison of seasonal and spatial variations of albedos from Moderate-Resolution Imaging Spectroradiometer (MODIS) and common land model, J. Geophys. Res., 108(D15), 4488 , doi:10.1029/2002JD003326.

G. Balsamo and E. Dutra, European Centre for Medium-Range Weather Forecasts, Shinfield Park, Reading RG2 9AX, UK. (emanuel.dutra@ ecmwf.int)
P. Bissolli, Deutscher Wetterdienst, KU23, Postfach 100465, D-63004 Offenbach am Main, Germany.

T. Jonas, WSL Institute for Snow and Avalanche Research SLF Flüelastr. 11, CH-7260 Davos, Switzerland.

S. Kotlarski and C. Schär, Institute for Atmospheric and Climate Science, ETH Zurich, Universitaetstrasse 16, CH-8092 Zurich, Switzerland.

P. M. A. Miranda and P. Viterbo, Centro de Geofísica da Universidade de Lisboa, Instituto Dom Luiz, University of Lisbon, Rua C Aeroporto, P-1749-077 Lisbon, Portugal. 